\title{
Synthesis of Three-Dimensional Reduced-Graphene Oxide from Graphene Oxide
}

\author{
Rasmeet Singh $\mathbb{D}^{1},{ }^{1}$ Sajid Ullah, ${ }^{2}$ Nikita Rao, ${ }^{1}$ Mandeep Singh $\mathbb{D}^{3},{ }^{3}$ Indrajit Patra $\mathbb{D},{ }^{4}$ \\ Daniel Amoako Darko $\mathbb{D}^{5},{ }^{5}$ C. Prince Jebedass Issac, ${ }^{6}$ Keyvan Esmaeilzadeh-Salestani $\mathbb{D}^{7}{ }^{7}$ \\ Rahul Kanaoujiya, ${ }^{8}$ and V. Vijayan' \\ ${ }^{1}$ Dr. S.S. Bhatnagar University Institute of Chemical Engineering \& Technology, Panjab University, Chandigarh 160014, India \\ ${ }^{2}$ Department of Water and Environmental Engineering, Nangarhar University, Jalalabad 2600, Afghanistan \\ ${ }^{3}$ School of Mechanical and Mechatronic Engineering, University of Technology Sydney, NSW 2007, Australia \\ ${ }^{4}$ Independent Researcher, National Institute of Technology Durgapur, Durgapur, West Bengal 713209, India \\ ${ }^{5}$ Institute for Environment and Sanitation Studies, College of Basic and Applied Sciences, University of Ghana, Legon, Accra, Ghana \\ ${ }^{6}$ Department of Chemistry, Voorhees College, Vellore 632001, Tamil Nadu, India \\ ${ }^{7}$ Chair of Crop Science and Plant Biology, Institute of Agricultural and Environmental Sciences, Estonian University of Life Sciences, \\ Friedrich Reinhold Kreutzwaldi 1, 51014 Tartu, Estonia \\ ${ }^{8}$ Synthetic Inorganic and Metallo-Organic Research Laboratory, Department of Chemistry, University of Allahabad, \\ Prayagraj 211002, Uttar Pradesh, India \\ ${ }^{9}$ Department of Mechanical Engineering, K. Ramakrishnan College of Technology, Samayapuram, Trichy 621112, India
}

Correspondence should be addressed to Rasmeet Singh; srasmeet9@gmail.com and Daniel Amoako Darko; dadarko@ug.edu.gh

Received 23 August 2021; Accepted 22 September 2021; Published 3 March 2022

Academic Editor: Lakshmipathy R

Copyright (C) 2022 Rasmeet Singh et al. This is an open access article distributed under the Creative Commons Attribution License, which permits unrestricted use, distribution, and reproduction in any medium, provided the original work is properly cited.

Carbon materials and their allotropes have been involved significantly in our daily lives. Zero-dimensional (0D) fullerenes, onedimensional (1D) carbon materials, and two-dimensional (2D) graphene materials have distinctive properties and thus received immense attention from the early 2000s. To meet the growing demand for these materials in applications like energy storage, electrochemical catalysis, and environmental remediation, the special category, i.e., three-dimensional (3D) structures assembled from graphene sheets, has been developed. Graphene oxide is a chemically altered graphene, the desired building block for 3D graphene matter (i.e., 3D graphene macrostructures). A simple synthesis route and pore morphologies make 3D reduced-graphene oxide (rGO) a major candidate for the 3D graphene group. To obtain target-specific 3D rGO, its synthesis mechanism plays an important role. Hence, in this article, we will discuss the general mechanism for 3D rGO synthesis, vital procedures for fabricating advanced 3D rGO, and important aspects controlling the growth of 3D rGO.

\section{Introduction}

Graphene is a 2D monolayer carbon, one-atom-thick material with superior thermal, mechanical, electronic, and optical properties [1-3]. Graphene along with its derivatives has shown immense applications in low-dimensional physics, energy storage, electronic devices, catalysis, sensors, medical equipment, etc. [4-6]. The excellent properties of graphene are important at nanoscale and must be harnessed for macroscopic applications. To become fully aware of the advanced properties of a single graphene sheet, it is important to integrate $2 \mathrm{D}$ graphene materials into $3 \mathrm{D}$ architectures [7]. For instance, in electrode materials and energy conversion devices, the $2 \mathrm{D}$ graphene sheets undergo restacking and their distinctive properties become less effective, leading to less efficiency than the theoretical values [8]. The way to overcome this drawback is to convert $2 \mathrm{D}$ layers into consistent and interconnected 3D frameworks that can be employed without concerning the restacking by retaining the distinctive properties of 2D graphene materials. In order 
to fully uncover the prospectus of graphene, both large scale production and conversion of individual graphene sheets into state-of-the-art multifunctional frameworks are required $[8,9]$.

The key step in manufacturing 3D graphene material (i.e., 3D rGO) and modulating its final structures and characteristics is the reduction of GO [10]. The reduction of GO is a chemical method to eliminate oxygen-containing parts on the GO plane. Majority of researches between the year 2006 and 2010 were focused on synthesizing highquality graphene sheets from GO [11]. Different strategies have been employed to reduce $\mathrm{GO}$, together with swift thermal reduction in inert atmosphere $[12,13]$; chemical reduction through series of reducing agents like hydrazine [14, 15], hydroquinone [16], $\mathrm{NaBH}_{4}$ [17], dimethylhydrazine [18], hot alkaline [19], ascorbic acid [20], etc. [21]; photocatalytic reduction [22]; hydro-/solvothermal technique [23, 24]; laser/flash light irradiation [25-27]; electrochemical reduction [28]; hydrogen-plasma/arc-discharge [29, 30]; microwave treatment [31], and combination of these techniques $[32,33]$.

A series of experiments have been conducted in the past few decades to study the methods for developing 3D rGO [34-36]. Reduction through thermal, chemical, hydrothermal, electrochemical, and photoinduced paths is a few of the effective techniques for the reduction of $3 \mathrm{D}$ GO or GO suspension with concurrent 3D construction. Freezecasting can be used for tuning the inside structure of GO or rGO gels along the developing ice as the in situ template. The annealing conditions are essential for the structural properties of obtained rGO sheets. The $\mathrm{H}$ atoms drive deoxygenation through a series of chemical reactions. The temperatures employed in this kind of process are generally higher than $500^{\circ} \mathrm{C}$ [29]. With exposure to reducing agents, the chemical reduction of GO proceeds with deoxygenation at low temperatures. However, the reducing agents may sometimes only reduce a certain class of oxygen-containing groups selectively (e.g., hydrazine was selective towards the epoxy groups) [37]. The majority of graphene materials obtained from GO exhibit a substantial number of holes, curvatures, functional groups, and defects on carbon sheets, resulting in a functionalized graphene with a $\mathrm{C} / \mathrm{O}$ ratio less than 1.5. Moreover, the defective graphene sheets obtained through thermal and chemical reduction display high agglomeration due to the presence of forces of attraction between layers and the reduction in hydrophilicity $[13,14]$.

Although the past few years have experienced rapid growth of $3 \mathrm{D}$ graphene materials and their several new synthesis techniques, still, the clear explanation and classification of 3D architectures have not yet been made. Furthermore, 3D graphene materials fabricated through various methods show distinctive properties and varying levels of performance for different applications. For tuning advanced 3D graphene structures for specific requirements, it is important to infer the relationship between 3D graphene properties and its performance, the mechanism involved in its formation, and key components determining the properties. In the last few years, there have been excellent and enormous review articles dealing with the synthesis of mac- roscopic 3D graphene $[4,7,9,38-41]$. The reviews generally focus on 3D graphene-based materials concerning the specific applications [42-46]. An overview of the 3D graphene family is still missing. Hence in this paper, we will discuss recently developed engineering strategies for synthesizing 3D graphene. Considering that a lot of work has been previously published in the field, we will present a detailed collection of advanced fabrication processes for 3D graphene. The primary focus is on the design considerations, formation principles, and engineering of $3 \mathrm{D}$ graphene-based architectures.

\section{Synthesis of 3D rGO}

2.1. Photoinduced Reduction. Photoreduction is a chemicalfree process for the reduction of GO with little physical contact, high efficiency, and high processing speed. In early 2008, photon energy was employed for reduction of GO in solutions with the involvement of semiconductor photocatalysts (like $\mathrm{TiO}_{2}$ ) under the irradiation of ultraviolet light [22]. This technique came out to be successful for developing the graphene/semiconductor composite. Further, it was established that GO reduction in a solution or over a substrate can be done directly under ultraviolet light with the side formation of $\mathrm{CO}, \mathrm{O}_{2}, \mathrm{H}_{2} \mathrm{O}$, and $\mathrm{CO}_{2}$ [47]. Meanwhile, xenon lamp-equipped photographic camera lights and laser lights were found to be capable of deoxygenating GO photos thermally. In such early reports, photoreduction of GO in dilute solutions only formed rGO suspension and not the desirable 3D rGO $[47,48]$, whereas with photoreduction of the GO film, a pore-rich 3D rGO was obtained. This also showed high conductivity and an expanded interlayer spacing [25-27].

Reduction of GO via photoenergy follows two types of mechanisms, i.e., photothermal effect and photochemical reduction. By principal, the GO reduction with irradiation of ultraviolet light with wavelength less than $390 \mathrm{~nm}$ is referred to as photochemical reduction [47]. For wavelengths longer than $390 \mathrm{~nm}$, the reduction of GO follows the photothermal effect. Because the photothermal effect involves high temperatures of $200-230^{\circ} \mathrm{C}$, the reduction of GO becomes effective. In case of laser lights, it creates an intensive heat zone by focusing the laser beam on the specific point. A large number of photons get absorbed upon strong irradiation by a pulsed laser and get converted to heat, leading to the rise of temperature on the sheet [49, 50]. However, photochemical processes can also occur via laser at long wavelengths (i.e., $1064 \mathrm{~nm}$ ) because of strong electron photon coupling and multiple photon absorption [51]. In both the mechanism paths, strong excitation of the GO surface renders the quick ejection of particles and leads to formation of plasma plumes. When energy transfers from plume to lattice, the oxygen group leaves $\mathrm{GO}$ with plume expansion. Thereafter, with formation of $\mathrm{CO}$ and $\mathrm{CO}_{2}$ and evaporation of internal water an interlayer pressure is produced which leads to the expansion of the rGO layer to form a porous structure $[27,52,53]$.

The photon-induced reduction is another method applicable on chemically reduced GO films. The energy of 
photons decomposes the residual chemical substances present in partially reduced GO. Among several sources of photon energy, laser lights are widely used due to their consistency, strong intensity, tunable power, and flexible pattering $[52,54,55]$. Laser scribing can easily achieve synchronous reduction with a GO film pattern $[56,57]$. The reduction degree of the GO film can be administered by varying the laser-processing variables (i.e., intensity, shifting pitch, scanning pitch) $[58,59]$. The $3 \mathrm{D}$ graphene patterns resulting from laser scribing have recently shown a great potential in biomedical applications like tissue engineering and cell culture [58]. Kaner and his research group [56, 57] fabricated $3 \mathrm{D}$ porous graphene sheets via laser-induced reduction of GO films. The process utilized a commercially available LightScribe DVD optical drive. Figure 1(a) shows the illustration for the whole process followed. Reduction with LightScribe gave 3D exfoliated sheets of $1520 \mathrm{~m}^{2} / \mathrm{g}$ specific surface area and $1738 \mathrm{~S} / \mathrm{m}$ electrical conductivity.

Atmosphere is an important factor for laser-induced GO reduction to control the degree of reduction of the resulting rGO film. The degree of reduction can be highly improved in an oxygen-free environment [60]. If the GO precursor is immersed in liquid nitrogen for laser reduction, the thermal expansion will be suppressed, resulting in a $3 \mathrm{D}$ rGO film with fewer defects and high conductivity compared to the film obtained in nitrogen [51]. Apart from the reduction of dense GO films/foams, laser intensity can also be directly employed for assembling $3 \mathrm{G}$ rGO in crystalline GO suspension. As shown in Figure 1(b), when the nematic lyotropic liquid crystal GO sheet is used as the precursor to be dispersed and ordered, by adjusting the focus and intensity of the laser, the arbitrary homogeneous $3 \mathrm{D}$ structures of the inside surface can be noticed [54]. Complex 3D assemblies like trefoil knots can be produced through voxel-by-voxel micropatterning of laser beams in both simple plane and across the thickness of the sample. This arrangement is different from laser-induced reduction of $\mathrm{H}_{2} \mathrm{O}$-reduced $\mathrm{GO}$ films and is favorable for error-free 3D localization in electronics and photonics.

2.2. Chemical Reduction. Reduction of GO through chemical routes is another major facile approach. In early research, hydrazine was used to obtain rGO dispersions to reduce dilute GO suspensions $[11,14,61]$. At a later stage, 3D graphene hydrogels/aerogels were synthesized with higher GO concentrated colloidal solution under mild reducing agents $[35,62,63]$. The reducing temperature is kept between 60 and $100^{\circ} \mathrm{C}$. The residue (i.e., reagent) and absorbed water are then removed by washing and lyophilization. A variety of reducing agents have been used to simultaneously reduce and construct 3D GO. These may include $\mathrm{Na}_{2} \mathrm{~S}$, HI [64], $\mathrm{H}_{3} \mathrm{PO}_{4} / \mathrm{I}_{2}$ [65], gelatin, and sodium ascorbate [66]. Shi and coworkers $[64,67]$ employed sodium ascorbate for the reduction of GO to develop a 3D graphene framework. Chen and Yan [64] and Zhang and Shi [68] used $\mathrm{NaHSO}_{3}, \mathrm{Na}_{2} \mathrm{~S}$, Vit. C, HI, and hydroquinone for reducing GO into $3 \mathrm{D}$ rGO. Both these researches claimed that the $\pi-\pi$ interlinkage among sheets may be a governing factor in deriving selfassembly of chemically reduced GO. This observation came in a similar manner to the hydrothermal approaches. Few research groups also claimed that function groups attached with reducing agents can be determined in $3 \mathrm{D}$ rGO sheet construction [69-71]. As the covalent bonds form between GO sheets and reducing agents, a few of the oxygencontaining hydroxyl and epoxy groups are substituted and the GO sheet is cross-linked [66, 72, 73]. To stimulate the cross-linking, carboxylic groups of reducing agents (i.e., oxalic acid and mercaptoacetic acid) can speed up the development of interlayer hydrogen bonds $[74,75]$. As stated by Liu et al. [66], gelatin amino groups induce the electrostatic attractions, ring opening reaction, and multiple hydrogen bonds of epoxy groups to collectively enhance the $3 \mathrm{D}$ development of rGO.

The evolution of $\mathrm{CO}$ and $\mathrm{CO}_{2}$ is usual in GO's chemical reduction. Evolution of favorable amounts of these gases helps in restacking of GO and rGO sheets and modulates the pore structure of 3D compounds. Furthermore, along with interactions among GO and reducing agents, water bubbles can additionally be introduced through a monitored heating temperature [76]. The total number of bubbles is important throughout the process. Less number of bubbles fails to suppress the restacking, while excess numbers can affect the self-assembly of $\mathrm{rGO}$ sheets. When $\mathrm{GO} / \mathrm{NaHCO}_{3}$ suspension is heated at $100^{\circ} \mathrm{C}$ in an open beaker, the number of bubbles accredited to the boiling of water is generated. On using concentrated reducing agents (i.e., hydrazine and $\mathrm{NaBH}_{4}$ ), microscopic voided irregular gels and rGO particles were seen because of substantial generation of gases [64, 77]. Hence, hydrazine is more favorable in reduction of GO into 3D structure.

Active metals like $\mathrm{Al}, \mathrm{Cu}, \mathrm{Al}, \mathrm{Fe}$, and $\mathrm{Co}$ can also be used as reducing agents for simultaneous reduction and formation of GO sheet $3 \mathrm{D}$ assembly on their surface. On the basis of redox reactions among metals and GO, the process of reduction, as well as assembly of GO, happens instantly at room temperature. However, the temperature can be raised to $60^{\circ} \mathrm{C}$ to speed up the process. Surprisingly, if a conductive substance is placed on the active metal substrate, no reduction in the development of $3 \mathrm{D}$ rGO assembly is seen (Figure 2) [78]. This favors the development of unique graphene structures like microtubes and micropatterns. Through slight tuning of the shape of metal deposited, these further can be fabricated into binder-free high performance rechargeable Li-ion batteries. In addition, flexible rGO 3D thin film devices can also be prepared by depositing active thin layers of metal substances on flexible substrates.

In addition, the vapors obtained from reducing agents can also be effectively employed in the reduction of both dried GO films and the sponges with side-by-side alterations in $3 \mathrm{D}$ structures. When a dense GO film is used as a precursor, its $3 \mathrm{D}$ configuration can be significantly altered during vapor-based reduction. Niu et al. [79] performed the reduction of filtrated GO film by positioning it on the top of a hydrazine monohydrate solution at $90^{\circ} \mathrm{C}$ for 10 hours (Figure 3). By controlling the concentration of the hydrazine monohydrate solution, the open pore structure can be tuned.

In spite of successful development of chemical reduction of GO, the changes involved in GO during the 


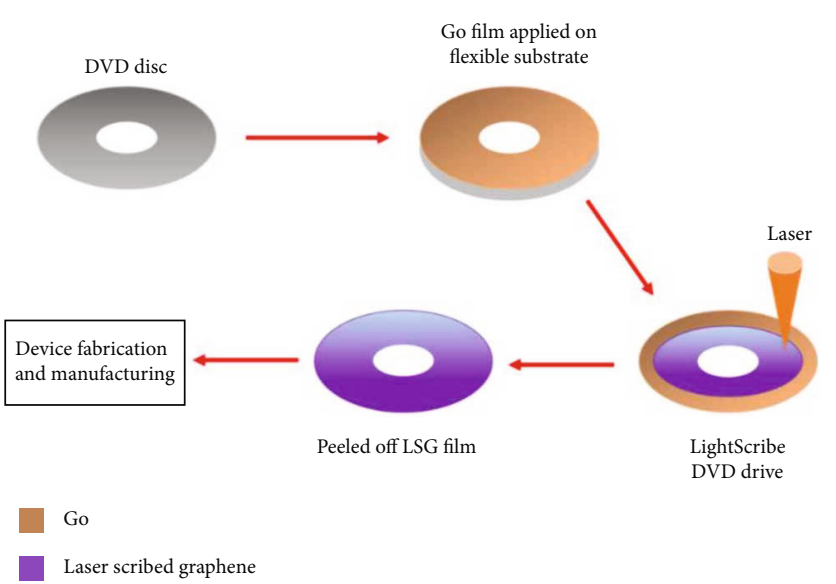

(a)

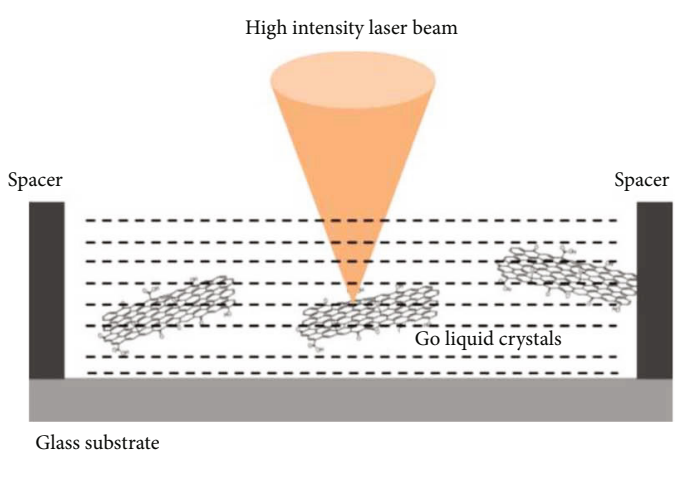

(b)

FIgURE 1: (a) A staggered representation of the laser-induced reduction of GO films. Adapted from [56], copyright 2012, American Association for the Advancement of Science. (b) Representation of ordered lyotropic nematic liquid crystal dispersion with GO leaf as precursor [54].
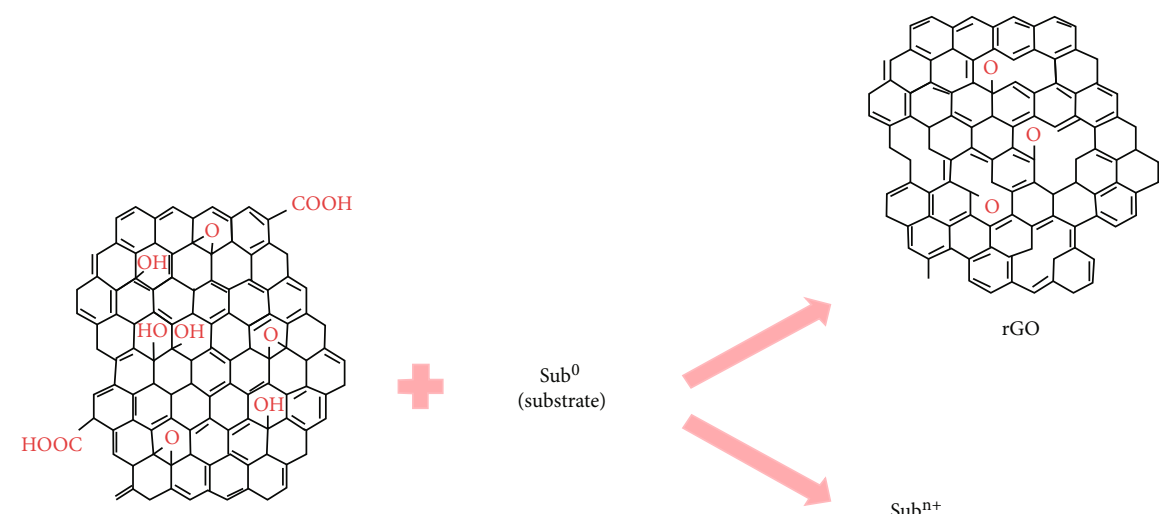

Sub $^{\mathrm{n}+}$

Figure 2: Diagram for substrate-assisted GO reduction and assembly. The active metal substrate $\left(\right.$ Sub $\left.^{0}\right)$ undergoes electron loss and gets oxidized to $\left(\mathrm{Sub}^{\mathrm{n}+}\right)$ ions [78].

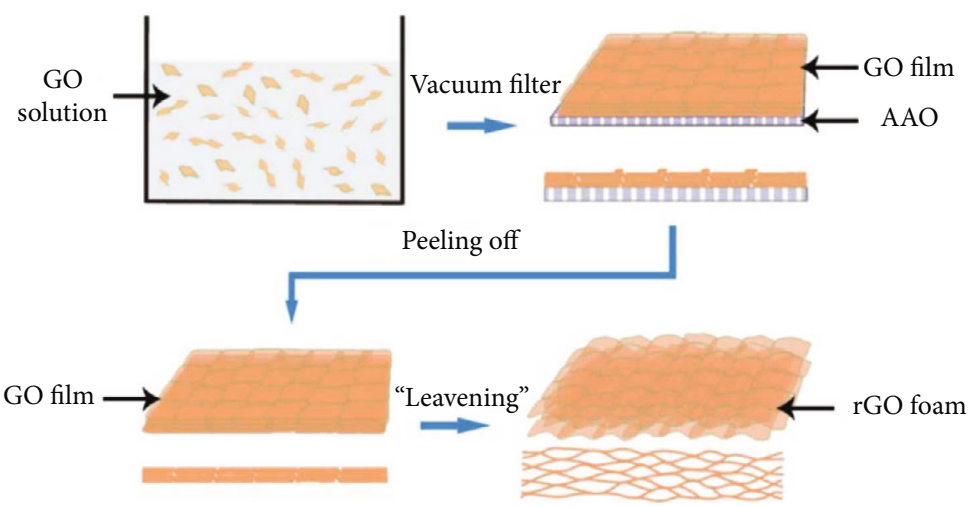

FIGURE 3: The figure illustrates the fermentation process to prepare rGO foam. Reprinted with permission from [79], copyright 2012, WileyVCH Verlag GmbH and Co. KGaA, Weinheim.

reduction process are still not fully understood. Hence, an effective method to minimize the amount of noncarbon impurities is required.
2.3. Electrochemical Reduction. This type of GO reduction is a popular method to directly synthesize electrodes with $3 \mathrm{D}$ graphene for electrochemical devices and electrochemical 
modifications (Figure 4) [62, 80-82]. The dispersed GO electrochemically reduces to precipitate on the cathode. Instead of packing in a face-to-face manner, the layers reinforce each other up, making a $3 \mathrm{D}$ graphene network rigidly stacked to the electrode $[62,81,83]$. This is also referred to as the direct growth of rGO sheets from the electrode surface. Producing a 3D graphene scaffold instead of a solid graphite layer means that a rapid reduction and acceleration process between the initial hydrophobic rGO layer and the GO hydrophobic layer is formed at a later stage. Along with this, hydrogen evolution happens under bias voltage, developing high porosity inside the deposited sheets [84].

Sheng and coworkers were the first ones to fabricate a graphene web on silver foil under $-1.2 \mathrm{~V}$ and $3 \mathrm{mg} / \mathrm{mL}$ GO suspension with $0.1 \mathrm{M} \mathrm{LiCLO}_{4}$. This prototype showed outstanding performance in an electric layer double capacitor having a capacitance of $283 \mathrm{mF} / \mathrm{cm}^{2}$ [62].

In electrochemically prepared $3 \mathrm{D}$ rGO materials, the electrodes are considered the most important components for 3D frameworks. Different materials like stainless steel mesh [82], Pt foil, Ni foam [81], and Au fiber [83] can be utilized as electrode bases. When graphene paper was employed as an electrode base, the highly porous rGOlayered structure was tightly attached to the substrate. This led to an all carbon electrode with excellent applications in flexible devices. On using $\mathrm{Ni}$ foam as the electrode substrate, the inner voids were filled with $\mathrm{rGO}$, creating an orderly porous structure having pore sizes in 100s of micrometers or submicrometers in the case of rGO sheets. The $3 \mathrm{D}$ rGO structures with varying hierarchical 3D frameworks can be prepared through preobtained 3D rGO materials as electrode bases.

The electrochemical method can also be employed to reduce electrode-precasted GO films [84, 86]. By doing so, the stacking of the GO sheet will be better controlled during the casting step and will ensure that the electrochemical process is effectively slowed down.

2.4. Thermal Expansion of GO Bulk. Thermal reduction or annealing at temperatures between 800 and $1000^{\circ} \mathrm{C}$ is the most standard, simple, and effective pathway to remove oxygen functional groups from GO. In the case of 3D graphene, annealing at high temperatures may result in thermal exfoliation, which further results in an expansion of dried and preshaped GO bulk precursors. GO precursors by thermal exfoliation include granular GO [87], irregularly aligned GO film [88], tape casting [10], and bulk GO materials [89].

In the process of thermal growth of bulk GO, the groups having oxygen (carboxyl, hydroxyl, carbonyl, and ether) are completely or partially eliminated or are transformed into stable bonds (i.e., anhydrides, quinone, and lactones) with the traces of $\mathrm{CO}_{2}, \mathrm{CO}$, and $\mathrm{H}_{2} \mathrm{O}[90,91]$. The clear-up amount of the graphene surface rises with increasing annealing temperature. At $1000^{\circ} \mathrm{C}$, traces of $\mathrm{C}-\mathrm{O}, \mathrm{OH}$, and $\mathrm{C}=\mathrm{O}$ are used to remove thermally unstable oxygen. Therefore, the conductivity of the GO sheet is greatly improved. In the meantime, the GO mass is transformed into the honeycomb 3D nanostructures with microscopic sheets and abundant pores. After undergoing this type of expansion, the distinct surface area could be further enhanced. Based on the precursor used and the reaction that followed, the surface area of 3D rGO frameworks could be maintained between 400 and $800 \mathrm{~m}^{2} / \mathrm{g}[90,91]$.

Thermal annealing is also employed for the reduction of 3D partially reduced GO and 3D GO architecture due to dry treatment and strong reduction. In such cases, the tuning of $3 \mathrm{D}$ structures becomes secondary. However, subjecting GO precursors instantly to high temperature regions by avoiding the ramping procedure with violet gas evolution might result in richer in-wall pores, resulting in high surface area. In certain situations, a thermal shock of $400^{\circ} \mathrm{C}$ can help crumpled graphene spheres to obtain a surface area of approximately $567 \mathrm{~m}^{2} / \mathrm{g}$, and heating the sample at the same temperature ensures a lower surface area of $344 \mathrm{~m}^{2} / \mathrm{g}$ [92].

2.5. Solvothermal and Hydrothermal Reduction. This reduction process was first developed to reduce GO into rGO sheets [23, 24]. As shown in Figure 5, Xu et al. [93] used a concentrated GO suspension to see reduction as well as self-assembly of GO in macroscopic 3D rGO hydrogels. Since then, these methods (i.e., hydrothermal and solvothermal) became well-liked methods for 3D graphene monolith production from GO sheets [34, 80, 94-96]. The reaction temperature is generally between 100 and $250^{\circ} \mathrm{C}$ in autoclave. Thermally induced supercritical water acts as a reducing agent in hydrothermal processes [97].

At the beginning of the hydrothermal process, the reduction in surface changes is noticed due to less carboxylic groups, attracting them to those with charges [98]. On extending the time of reaction, majority of carboxylic groups are removed and the hydrophobicity, $\pi-\pi$ stacking interactions, and electrostatic attractions are enhanced, making the rGO sheet assembly tightly interconnected as a 3D framework (Figure 6) [93]. As the oxygen-based groups decrease, $\mathrm{CO}_{2}$ becomes a predominant product along with traces of CO and fragments of organic acids $[99,100]$.

Although GO sheets are not completely removed after water heat treatment, as a result, both hydrogen bonds and $\pi-\pi$ interactions among oxygen-functional groups add to the cross-linking of 3D sheets in monoliths [101]. Also, the size, concentration, and surface of GO sheets in the first GO suspension could be significant in enhancing the density and structure of final 3D rGO gels.

Replacing $\mathrm{H}_{2} \mathrm{O}$ with another organic solvent by solvent thermal reduction of GO lowers the temperature and hardly induces the self-assembly properties of the GO sheet [102, 103]. When compared to the hydrothermal technique, the high self-generated pressure and low surface energy of the solvent in solvothermal processes could result in high efficiency fabrication and reduction of GO sheets [103, 104]. Hence, the $3 \mathrm{D}$ rGO materials resulting from solvothermal reduction display higher conductivities with lower surface areas and thick walls. Solvothermal reduction employing ethanol as a solvent results in the development of $3 \mathrm{D}$ rGO aerogel. An important observation noted was that the super-elasticity and Poisson's ratio of this material became almost zero, which can never be achieved with water as a solvent at the same reaction conditions [105]. However, the 
GO

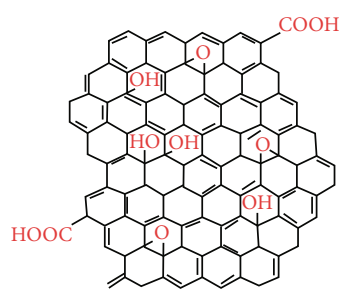

rGO

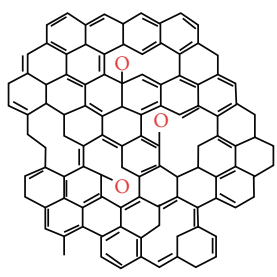

$\mathrm{O}^{2}$ groups removed

$\mathrm{sp}^{2}$ hybridization restored

FIgURE 4: Idea behind the electrochemical reduction of GO into rGO [85].

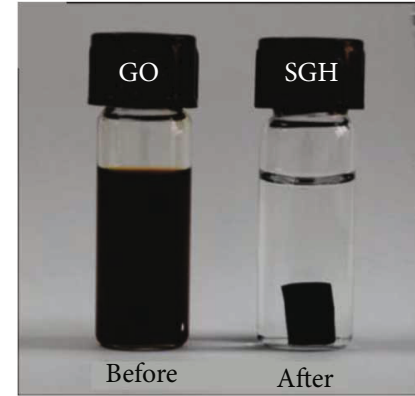

(a)

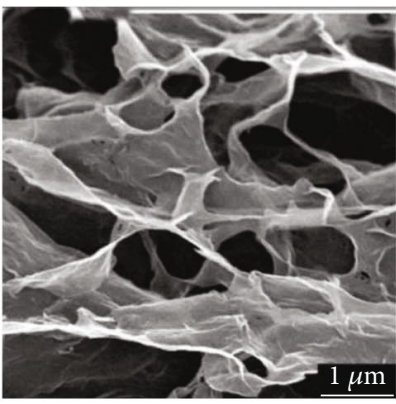

(c)

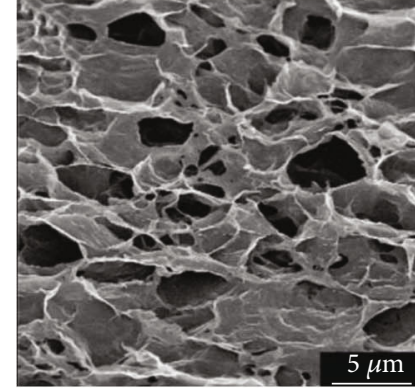

(b)

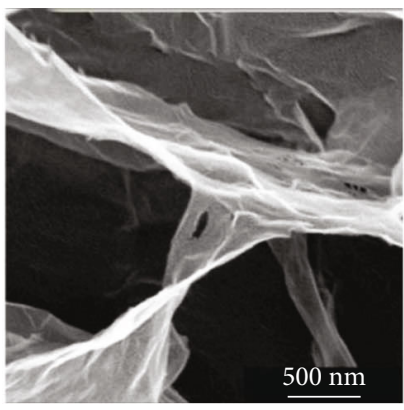

(d)

FIgURE 5: (a) A homogeneous aqueous dispersion of $2 \mathrm{mg} / \mathrm{mL}$ GO before and after hydrothermal reduction at a temperature of $180^{\circ} \mathrm{C}$ for $12 \mathrm{~h}$. (b-d) SEM images at different magnifications of the microstructure inside self-organized graphene hydrogels. Reproduced from [93], copyright 2010, American Chemical Society.

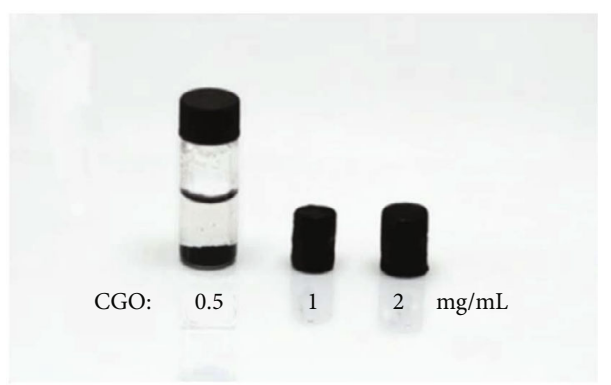

(a)

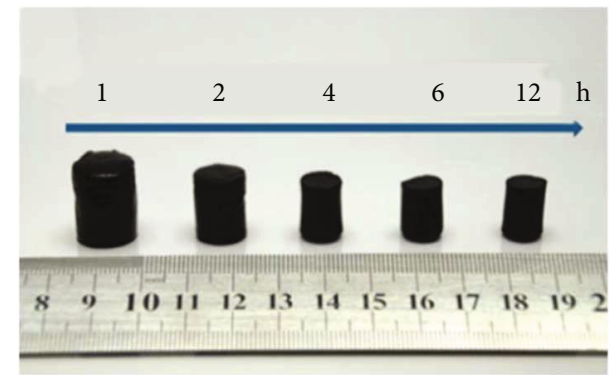

(b)

FIgUre 6: (a) A product manufactured by hot water reducing a GO dispersion at $180^{\circ} \mathrm{C}$ for 12 hours at different $\mathrm{C}_{\mathrm{GO}}$ s. (b) Photographs of products manufactured by hydrothermal reduction of $2 \mathrm{mg} / \mathrm{mL} \mathrm{GO}$ at $180^{\circ} \mathrm{C}$ varying time limits. Reproduced from [93], copyright 2010, American Chemical Society. 
interaction mechanism between GO sheets and solvents in the solvothermal process still remains to be explored.

The drying path of hydrothermally and solvothermally reducing GO is an important factor in deciding the final 3D structure. If processed under general thermal conditions, the 3D rGO hydrogel will bear the acute volume shrinkage and structural cracking. This happens mainly because of large capillary pressure from solvent evaporation and the structural thickness. The capillary pressure is controlled by either freeze-drying or supercritical $\mathrm{CO}_{2}$ drying. Here, $\mathrm{H}_{2} \mathrm{O}$ is replaced by ice or supercritical $\mathrm{CO}_{2}$ liquid. This is all because they do not react well with graphene walls [77]. The capillary pressure of solvent evaporation is correlated with solvent surface tension, angle of contact, and pore radius in accordance with the Laplace formula. Various schemes can be implemented to achieve ambient drying while maintaining the $3 \mathrm{D}$ structure. Meanwhile, the stiffness of the materials depending on wall thickness and the intersheet linkage firmness can be improved by resisting the capillary pressure [106].

Further, the hydrothermal and solvothermal processes are efficient in reducing and activating GO with performed $3 \mathrm{D}$ structures [107]. In such cases, the 3D structures will be minutely affected by reduction, which normally are determined during the preshaping process. However, the degree of reduction of final $3 \mathrm{D}$ rGO materials is slightly low due to the low temperature of hydrothermal and solvothermal reactions. To further eliminate the functional groups, annealing or chemical reduction can be used as a posttreatment reaction. This will also help to restore the $\pi$-conjugation and improve the electrical conductivity $[105,107]$.

The hydrothermal and solvothermal processes can also be used to produce $3 \mathrm{D}$ graphene-based composites. This may include $3 \mathrm{D}$ graphene doped with nanoparticles like $\mathrm{Fe}_{3} \mathrm{O}_{4}$ and $\mathrm{Co}_{3} \mathrm{O}_{4}$ on a composite layer [108]. Compared with the hydrothermal pathway, under the influence of the solvent, the nanoparticles are more uniformly wrapped by the solvothermal pathway in situ by binding with ethanol, resulting in more intimate contact with $3 \mathrm{D}$ rGO.

2.6. Freeze-Casting Process (Pre- or Post-reduction). Freezecasting is a widely used, readily accessible solution phase method for casting GO and partially rGO suspensions or gel forms. It depends on the ice crystallization point. During the procedure, phase separation leads to the repulsion of $\mathrm{GO} /$ partially reduced GO sheets from developing ice crystals and gets accumulated in a continuous $3 \mathrm{D}$ manner at the interspaces between developed ice [109-111]. The concentration of GO/partially rGO sheets must outgrow the percolation threshold in order to build an interconnected structure. After obtaining a porous GO monolith through freeze-casting, further reduction is required to get a $3 \mathrm{D}$ rGO framework. The reduction operation is important to adjust the surface properties of the sheet. However, since the porous composition of $3 \mathrm{D}$ rGO is stationed in the freeze-casting process, this may slightly affect the microscopic morphology.

In suspensions, the chemical properties of GO sheets play another major role in the freeze-casting process. Direct freezing yields GO randomly oriented brittle monoliths $[112,113]$, while a super-elastic honeycomb-like cellular orientation results when freeze-drying is done either for GO-filtered gel or specific partially reduced GO dispersion $[106,109]$. This difference among monoliths of GO and partially reduced GO occurs due to improved $\pi-\pi$ attractions of partially reduced GO sheets [106]. Additionally, as shown in equation (1), as per the lowest energy principle, for GO or partially reduced GO particles hindered due to the growth of ice, the free energy of interface related with $\mathrm{GO} /$ partially reduced GO $\left(\sigma_{\mathrm{i}}\right)$ has to be greater than the sum of both water-GO/partially reduced GO $\left(\sigma_{\mathrm{w}}\right)$ and icewater interface $\left(\sigma_{\mathrm{iw}}\right)$.

$$
\Delta \sigma=\sigma_{\mathrm{i}}-\left(\sigma_{\mathrm{w}}+\sigma_{\mathrm{iw}}\right)>0
$$

After partial reduction, micro-3D partially reduced GO architects were seen in place of lamellar 2D GO sheets. Thus, a strong deriving force $(\Delta \sigma)$ to accumulate building blocks at ice solidification form was produced in the arrangement with partially reduced GO (Figure 7). This further helped in the super-elastic structure of the partially reduced GO monolith [109]. Also, the hydrophobic properties of the partially rGO sheet can be adsorbed on the surface of the ice by the abundant oxygen-containing groups and dominate the growth of ice crystals $[114,115]$. As the water solidification in partially reduced $\mathrm{GO}$ suspensions gets completed, the 3D crystals are positioned and will interchange a little in thawing and future reductions. The $3 \mathrm{D}$ rGO prepared this way is able to maintain its structural integrity with a load, i.e., 450,000 times its own weight with instant recovery from $480 \%$ compression [106].

Also, the freezing point is essential to tune the $3 \mathrm{D}$ structure of freeze-casting rGO. It directly gets involved with the manipulation of the growth behavior of ice crystals. At high temperatures, the growth of crystals gets more favorable and leads to the production of large lamellar ice crystals. However, at lower temperatures, nucleation of ice dominates and spreads ice crystal nuclei throughout the material. Hence, the wall thickness, total size, and pore structure can be highly influenced by monitoring the freezing temperature $[116,117]$.

In addition, through monitoring the temperature distribution in the freezing system, Bai's research group successfully developed a bidirectional freezing technology and tried it on synthesizing 3D rGO with a biomimetic lamellar structure [118, 119]. Recently, Wang and coworkers adopted this unique bidirectional temperature control method to achieve a fan-shaped arrangement of GO [115]. The vessel used a copper rod with a cylindrical hole. Because the bottom of the cylinder was immersed in liquid nitrogen, the top was cold so the inside GO suspension had a two-way temperature gradient (i.e., "bottom to top" and "outside to inside") (Figure 8). The distinctive temperature gradients enabled the crystallization in a different manner than a conventional freezing process. To get the desired GO aerogel (i.e., radially aligned channels), a small quantity of ethanol was further added. After reduction by hydrazine vapor and drying in a complete vacuum, the prepared rGO aerogel 


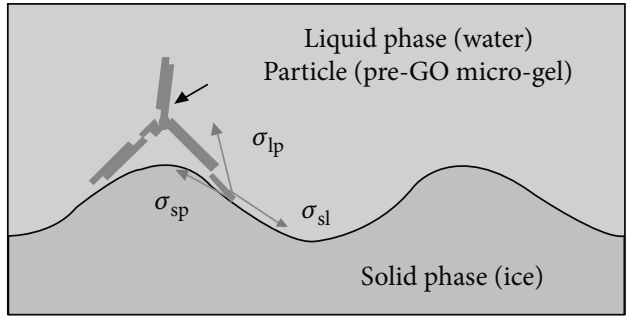

(a)

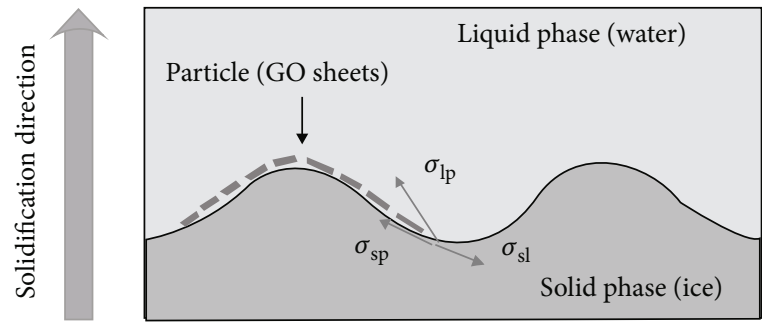

(b)

Figure 7: Diagram of the interfacial free energy between the solidification surface of the solvent and the particles present in the suspension. (a) Prereduced GO microgel system. (b) GO sheet system. Reproduced with permission from [109], copyright 2016, Wiley-VCH Verlag $\mathrm{GmbH}$ and Co. KGaA, Weinheim.

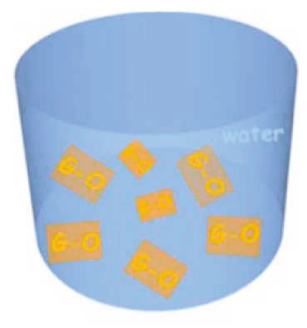

G-O aqueous dispersion

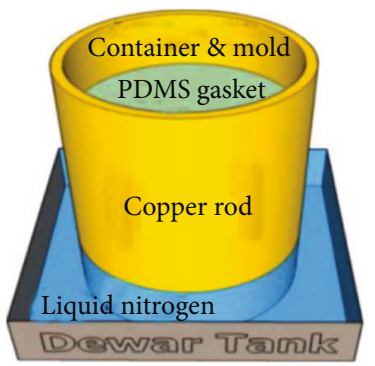

(b)

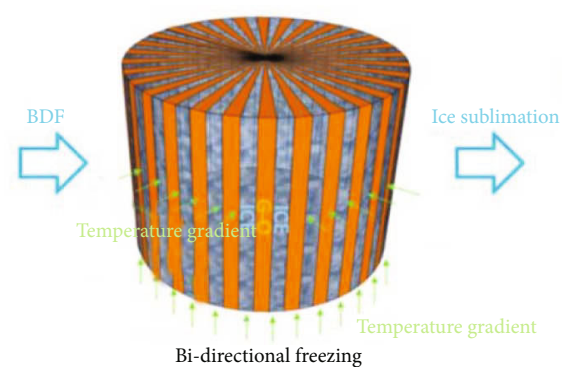

(a)

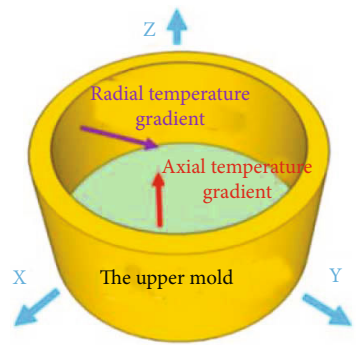

(c)
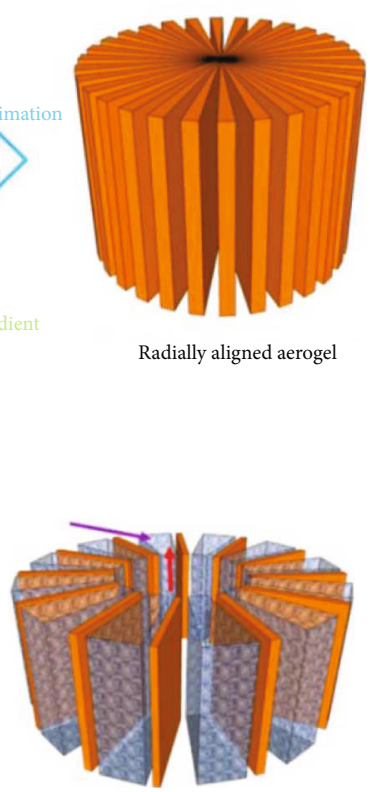

(d)

Figure 8: (a) Manufacturing process planning. (b) A refrigeration unit to create a radial structure with a Cu rod with a hollow top. (c) Two temperature gradients caused by the $\mathrm{Cu}$ type present upside. (d) Model of ice crystals developing along the radial direction under the influence of two temperature gradients. Orange sheets represent dispersed GO sheets. Reproduced from [115], copyright 2018, American Chemical Society.

displayed high porosity and specific pore orientation and was highly ordered. After 1000 compression cycles with $50 \%$ strain, only $8 \%$ of the total structural permanent deformation was noted. To further promote the surface activation, $\mathrm{KOH}$ solution was used to combine ultralightness and excellent mechanical strength. This substance may selectively adsorb organic pollutants present in water.

Additionally, other solvents can also be employed for the freeze-casting process. These may include organic solvents with high vapor pressure and melting point slightly higher than the room temperature (for example room-temperature freeze gelation) [120]. In comparison to freeze-drying using water, the room-temperature freeze gelation highly reduces the energy consumption. However, the cost of organic solvents could be an issue for this to develop.
2.7. 3D Printing before Reduction. Compared to other strategies, 3D printing prepares a 3D rGO architecture with more complex shapes. Extrusion-based $3 \mathrm{D}$ printing is the preferred printing strategy for 3D rGO synthesis [121, 122]. A newly developed technology, optical 3D printing, controls structures more precisely down to the micrometer scale [123].

2.7.1. Extrusion-based $3 D$ Printing. This technique has recently become popular in the on-demand engineering of graphene and composite 3D macrostructures. 3D printing can also be called robot-assisted deposition, robocasting, direct ink writing, and continuous extrusion [124]. Wetspinning technology can be used for printing of $500 \mathrm{~nm}$ graphene nanowires [125], but this is more often used to get 
compounded 3D structures through filaments extruded from nozzles, which merge together via a "layer-by-layer method" [126]. Procuring a GO suspension with specific rheology is very important to use $3 \mathrm{D}$ printing to its fullest. The extruded filaments are expected to behave as a shearthinning fluid with viscoelastic characteristics that adhere with neighboring layers while maintaining the shape after printing and pressing upon by printed filaments [122].

Fragment size and GO concentration play important roles in the elastic properties of GO inks. The elastic property $(y)$ for a concentrated GO suspension is denoted by $[127,128]$

$$
y=k\left(\frac{\Phi \times D_{\text {sheet }} \times S_{\mathrm{sa}} \times \rho}{3}-1\right)^{x},
$$

where $k$ is the constant, $x$ is the scaling factor, $\Phi$ is the GO concentration, $\rho$ is the density of the solvent, $D_{\text {sheet }}$ is the lateral size of the GO sheet, and $S_{\mathrm{sa}}$ is the specific surface area of the GO sheet.

Zhu and team stated that the GO suspension with 150$400 \mathrm{~nm}$ lateral size behaves as a non-Newtonian fluid at a $20 \mathrm{mg} / \mathrm{mL}$ concentration [121]. Increase in concentration further improves the GO viscosity and enhances its printability. At similar concentration, the $5-50 \mu \mathrm{m}$ flake size GO shows high viscosity and forms a robust 3D structure $[129,130]$.

In order to further improve the printability of GO suspensions, modified GO suspensions together with additives are widely used as printing inks $[122,131]$. García-Tuñon et al. [122] developed a $\mathrm{pH}$-sensitive polymer functionalized with GO suspension to apply in 3D printing for the preparation of the 3D rGO monolith. Therefore, the suspension can be adjusted by adjusting the $\mathrm{pH}$ for accurate $3 \mathrm{D}$ printing. Optimized suspension produces a branched polymer/GO surfactant network formed by noncovalent interactions. This network possesses shear-thinning behavior and predominates with solid-like characteristics up to $1 \%$ of strain, enabling easy flow of gels in nozzles of diameter of $100 \mu \mathrm{m}$. Since silica powder can transmit additional shear-thinning behavior and shear-yield stress, Zhu and coworkers further used hydrophobic fumed silica powder as fillers to improve the viscosity of GO ink $[121,131]$. In addition, the team also introduced basic compounds, such as $\left(\mathrm{NH}_{4}\right)_{2} \mathrm{CO}_{3}$ and $\mathrm{RF}$ catalyst compounds, to effectively regulate the cross-linking of GO sheets by adjusting the surface charge and covalent bond formation.

These polymers and solid additives can interfere with the mechanical properties and conductivity of printed rGO structures. Furthermore, treatments to recover the solid add-ons are rather tedious. Hence, greener ionic additives (i.e., $\mathrm{Ca}^{2+}, \mathrm{Mg}^{2+}, \mathrm{Fe}^{3+}$, etc.) are investigated to see the rheological behavior of the GO ink. A minute amount of $\mathrm{Ca}^{2+}$ ions enhanced the viscosity and viscoelasticity of GO dispersion [132]. With increasing $\mathrm{Ca}^{2+}$ concentration, the yield modulus and storage of GO also increases. GO sheets with mild ammonium-induced cross-linking can be obtained by adding urea into the GO suspension [133]. These mixtures are easily pushed and converted into tough filaments that exhibit high viscosity and shear behavior.

Apart from adding additives, a special type of solvents can also be employed to obtain printable GO ink. These solvents are liquid and solid at moderately high temperatures (i.e., $50-120^{\circ} \mathrm{C}$ ) and room temperature, respectively [120]. Hence, just mild temperature monitoring is required for tuning the rheology of the suspension to get the required $3 \mathrm{D}$ printing. Finally, the solvent is evaporated in a vacuum (even at room temperature), leaving a pure GO framework.

The filaments in extrusion-based 3D printing nozzles are typically extruded in air $[122,130]$ or liquid [121]. In liquid baths, organic solvents are preferred due to their lesser density than water and immiscibility with aqueous ink [131]. Zhang et al. [134] used an ice bath at $-25^{\circ} \mathrm{C}$ for the ink. The low temperature quickly solidifies the ejected GO suspension, so that a lower concentration of $110 \mathrm{mg} / \mathrm{mL}$ of GO precursor can be applied. This process achieves a fine $3 \mathrm{D}$ structure due to melting and fusion operations with few voids.

2.7.2. Optical $3 D$ Printing of $r G O$. The combination of photoexcited polymerization with layer-by-layer $3 \mathrm{D}$ printing can be used to synthesize complex macro-3D architectures of rGO [123]. As shown in Figure 9, firstly, a 1 wt.\% dilute GO dispersion was mixed with $12 \mathrm{wt} . \%$ photocurable acrylates and $2-4 \mathrm{wt} . \%$ photoinitiator to get a specific type of photocurable resin. This resin is able to solidify instantly under light-initiated polymerization. A thin layer of resin forms on it when a substrate is placed on it. Then, the top resin layer is cross-linked and solidified by patterned light irradiation. A further top layer of suspension was seen for further patterning and reduction targets. A light of $405 \mathrm{~nm}$ wavelength was rearranged with a spatial light-modulator where the targeted $2 \mathrm{D}$ image patterns were sliced and $3 \mathrm{D}$ structures were the input. Hence, such a process could lead to arbitrary complex 3D structures with controlled size at the micron scale. The resolution of the signal wire is maintained at approximately $10 \mu \mathrm{m}$ with a guide hole size of $60 \mathrm{~nm}[123]$.

2.8. Wet-Spinning before Reduction. The wet-spinning of GO before undergoing chemical, hydrothermal, and thermal reduction is a popular method for developing $3 \mathrm{D}$ rGO structures like 3D rGO fabrics, films, cylinders, spheres, and fibers $[86,135-137]$. Xu and Gao were the first ones to synthesize continuous graphene fibers independent of any support surfactant or polymer through a wet-spinning GO chiral liquid crystal technique in a coagulation bath containing 5 wt. $\% \mathrm{NaOH} / \mathrm{CH}_{3} \mathrm{OH}$ solution. Further, a chemical reduction method using $40 \%$ HI solution was followed. GO's liquid crystal follows the twisted boundary phase as the model. The obtained graphene fibers exhibited 7.7 GPa Young's modulus, $140 \mathrm{MPa}$ fracture strength, an approximate $5.8 \%$ fracture elongation, and $25,000 \mathrm{~S} / \mathrm{m}$ of high conductivity [138].

In the spinning process, the GO suspension concentration is an important factor for the development of continuous fibers. The lamellar structured liquid crystals of GO 

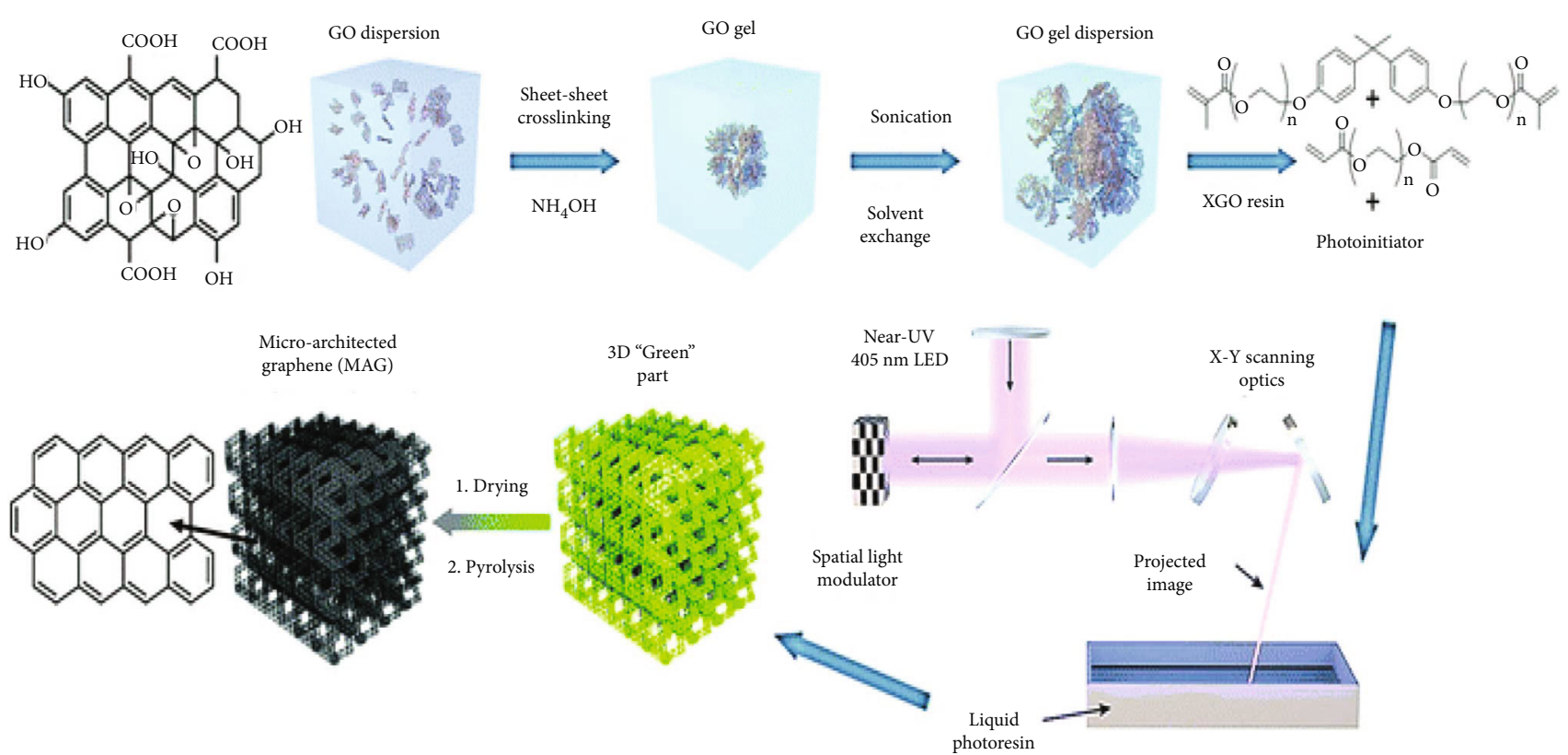

Figure 9: Optical 3D printing process flowchart. Reproduced with permission from [123], copyright 2018, Royal Society of Chemistry.

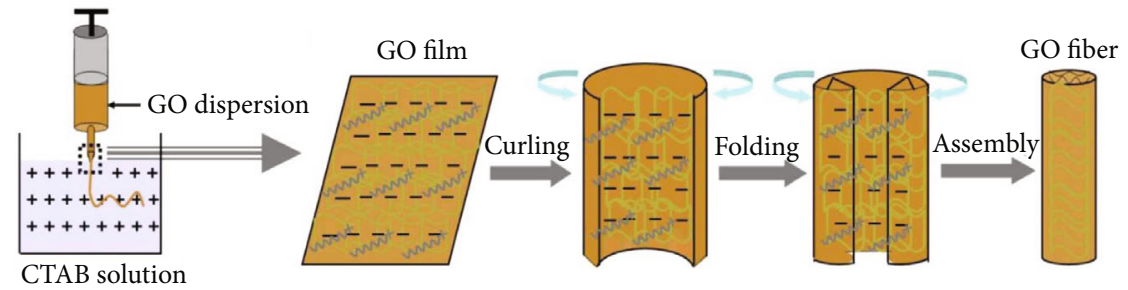

Figure 10: (a) Typical apparatus representation for wet-spinning GO fibers. (b) Illustration of the assembly mechanism of the GO fiber. Reproduced with permission from [136], copyright 2012, Springer Nature.

enables the dispersion at high concentration, leading to strong interactions among GO sheets, thus stimulating the alignment and coagulation of formed sheets. Otherwise, brittle fibers and collapsed belts can result from low concentrations of GO. The spun liquids are targeted in the coagulation bath, where they exert influence on external and internal formations of spun GO fibers. Figure 10 proposes the mechanism for the formation of graphene fibers. A multilayer GO film is first produced through the repulsions among negatively charged GO sheets. Further, as the charge neutralizes between adsorbed low-concentration hexadecyltrimethylammonium bromide solution and the GO sheets, the film turns into a bent and folded form. Continuous curling and folding eventually result in highly aligned fine particles. Spinning liquid GO crystals in liquid nitrogen and additional freeze-drying produces single-core dense-shell graphene fibers [135]. The internal arrangement of the $\mathrm{GO} / \mathrm{rGO}$ sheet is uniform, and the porous fiber exhibits a high specific surface area of about $884 \mathrm{~m}^{2} / \mathrm{g}$, a tensile strength close to $188 \mathrm{kNm} / \mathrm{kg}$, and a high electrical conductivity of $300 \mathrm{kNm} / \mathrm{m}$ of $4900 \mathrm{~S} / \mathrm{m}$.

From the perspective of wet-spinning instrument design, the size and shape of the nozzle is an important factor to define the comprehensive shape of final GO/rGO fibers [135]. The $60 \mu \mathrm{m}$ nozzle generates porous graphene fibers with a diameter of $100 \mu \mathrm{m}$, while the $1 \mathrm{~cm}$ nozzle results in $1 \mathrm{~cm}$ diameter graphene hollow fibers (Figure 11). A double capillary coaxial spinneret can produce graphene-based hollow fibers, while collar-shaped fibers can be obtained by GO suspension (Figure 12) [128]. A geometrically confined flat nozzle of line-shape can give continuous GO hydrogen films $[139,140]$.

The rotation process can also be manipulated to obtain 3D graphene materials of various shapes and structures. Figure 13 shows the blending of super-elastic graphene aerogel millispheres via spinning the liquid crystals of GO into a rotating coagulation bath. The shear force on the small nozzle makes the outer surface of the hydrogel have an obvious orientation, and after drying and annealing, a continuous shell and core of the cellular structure are formed. The resulting rGO millispheres show high mechanical strength and pressure flight behavior, with high jumping speed. However, a low specific surface area of $37 \mathrm{~m}^{2} / g$ was seen, indicating the presence of bulky/graphene walls.

The reduction after wet-spinning is important for evaluating the characteristics of 3D rGO materials $[86,109,140]$. 


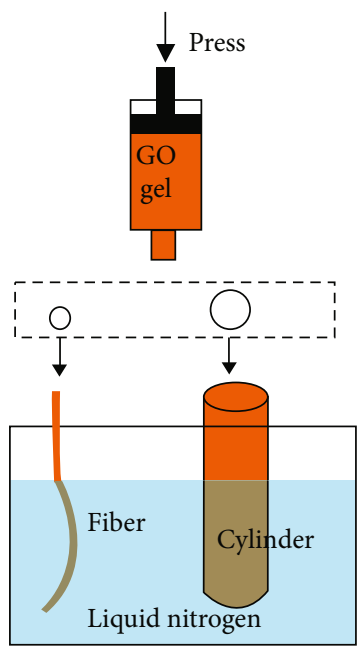

(a)
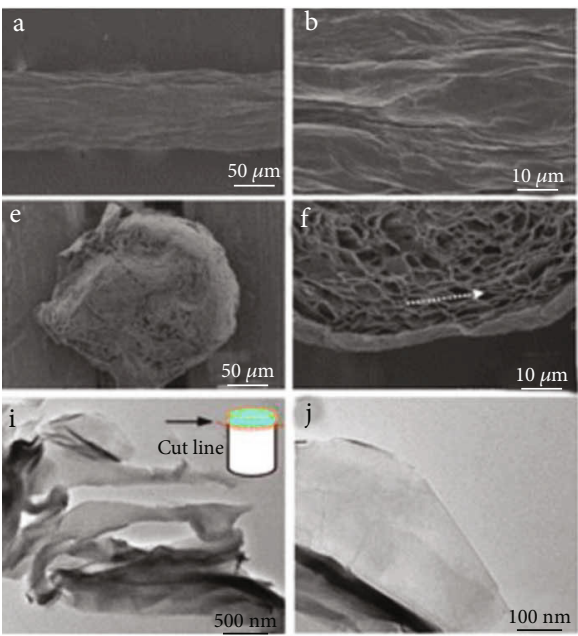

(b)

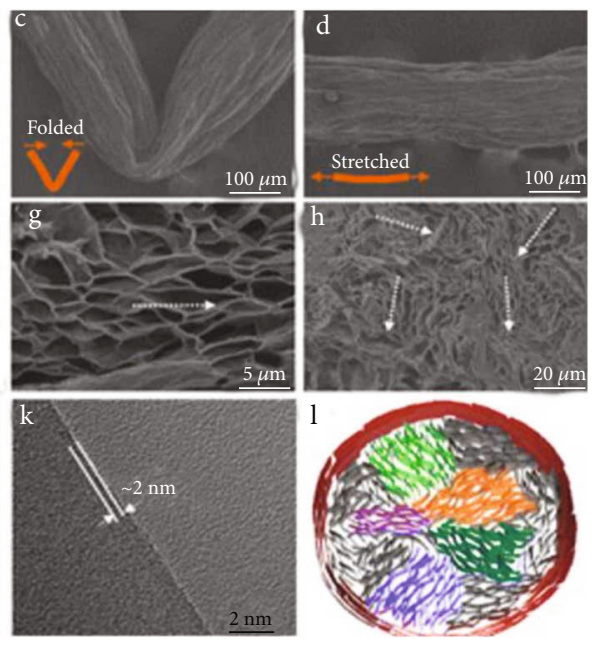

(b)

FIGURE 11: (a) Manufacturing plan for GO porous fiber and GO porous cylinder. (b) SEM images of the surface of reduced graphene porous fibers $(a, b)$ and folded/stretched reduced graphene porous fibers $(c, d)$. (e-h) SEM image of the fractured form of reduced graphene porous fibers. The arrow indicates the direction of sorting the reduced graphene sheet. (i-k) TEM image of destroyed reduced graphene porous fibers embedded in epoxy resin. (l) Schematic core of reduced graphene porous fibers and GO porous fiber-shell structure model. Reproduced from [135], copyright 2012, American Chemical Society.

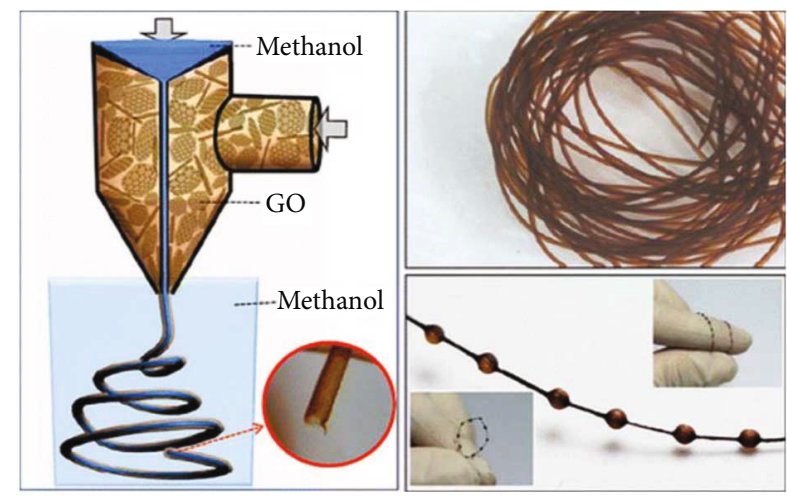

(a)
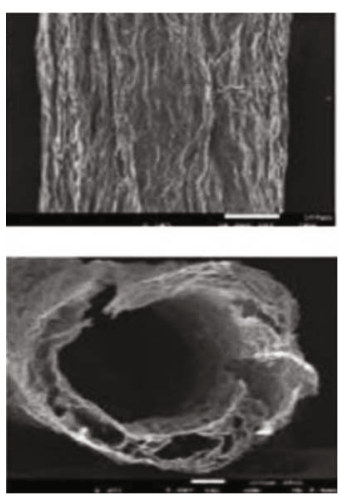

(b)

FIGURE 12: (a) Double-capillary spinneret to straightly spin GO hollow fiber conversion setup. (b) SEM representation of the fiber surface with section. Reproduced from [137], copyright 2013, American Chemical Society.

Optimization of the reduction process increased the specific surface area of hydrothermally activated graphene fiber fabrics by $370 \%$ and also highly influenced its conductivity [107].

\subsection{Antisolvent and Capillary Shaping before Reduction.} Crushing one or several GO sheets into spherical particles is another way to minimize sheet accumulation under compression. In order to achieve crumpling, forces from the external environment must be applied to the static GO suspension. Desired particles can be obtained through antisolvent methods and the capillary compression [92, 141-143].

Antisolvent precipitation is considered as an effective method to produce crumpled GO papers. The GO sheets are randomly distributed in the aqueous solution, because the oxygen-containing functional groups on the surface of
GO can physically and chemically bind with $\mathrm{H}_{2} \mathrm{O}$ molecules. Later, after drying, these sheets are arranged in a uniformly stacked GO film. Hexane is considered a nonpolar aprotic antisolvent which prohibits interacting with functional groups present on GO. On its addition into the GO/ethanol suspension, it replaces the ethanol molecules present around $\mathrm{GO}$, resulting in sturdy in-plane interactions of functional groups leading to crumpling of GO sheets; hence, the nonstacked GO gets formed with a large pore volume [142]. The thermally reduced nonstacked rGO shows a stable structure and $1435 \mathrm{~m}^{2} / \mathrm{g}$ of surface area, which is much higher than the rGO produced without using an antisolvent (i.e., $\sim 311 \mathrm{~m}^{2} / \mathrm{g}$ ). Wu et al. [144] developed a similar antisolvent precipitation method using precursor as a GO-based $\mathrm{Na}_{2} \mathrm{SO}_{4}$ mixture, alcohol as an antisolvent, and $\mathrm{NaOH}$ as a neutralizer. After the experiment, it was concluded that not 

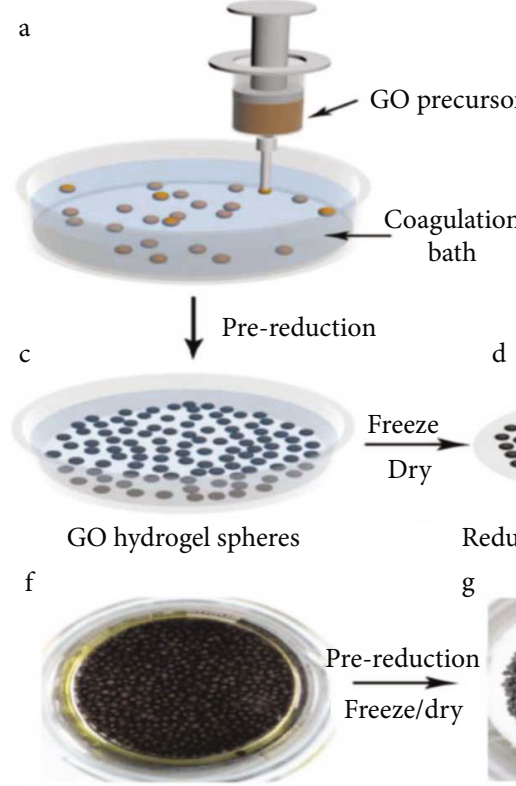

GO hydrogel spheres

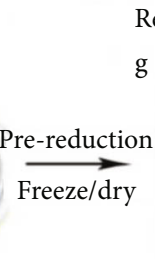

Reduced GO aerogel spheres

Reduced GO aerogel spheres b

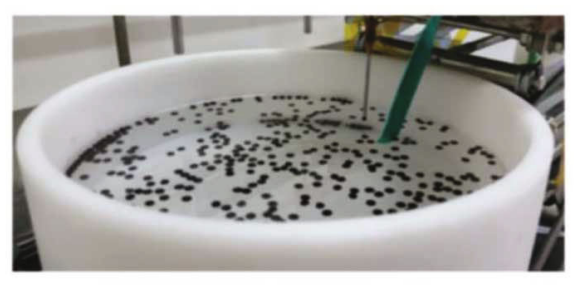

e

d
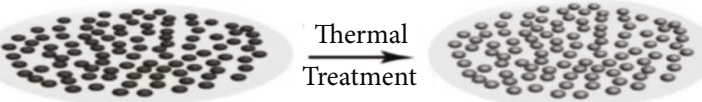

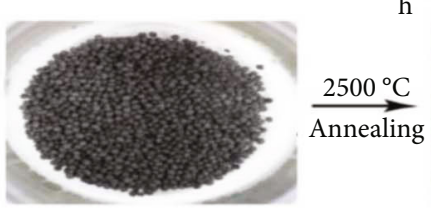

Graphense aerogel spheres
Graphense aerogel spheres

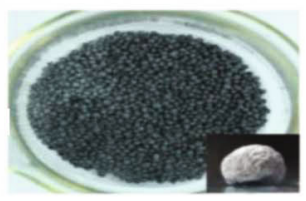

FIGURE 13: $(\mathrm{a}, \mathrm{b})$ Wet-spinning process represented for GO hydrogel spheres. (c-e) Synthesis process of graphene aerogel spheres using GO hydrogel spheres. (f) Newly obtained GO hydrogel spheres. (g) rGO aerogel spheres. (h) Graphene aerogel spheres after $2500^{\circ} \mathrm{C}$ annealing. Reproduced with permission from [140], copyright 2017, Wiley-VCH Verlag GmbH and Co. KGaA, Weinheim.

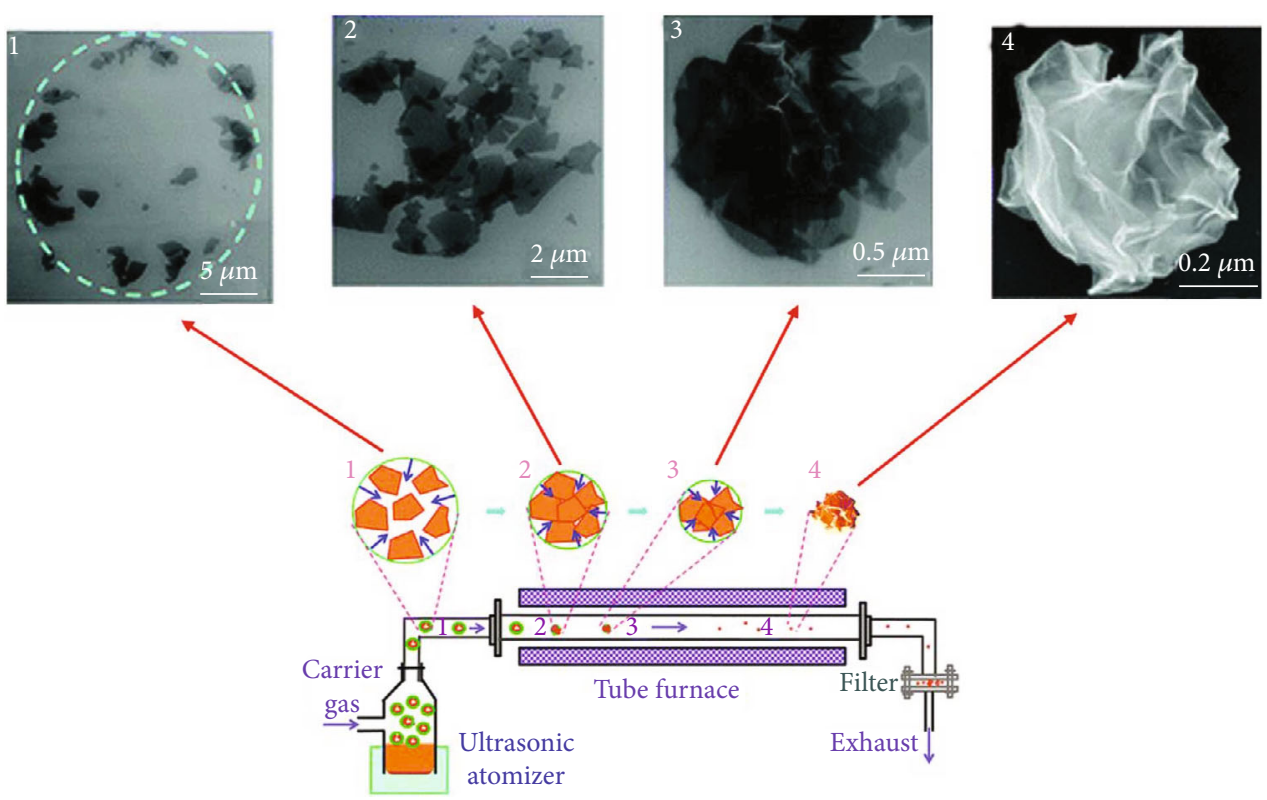

FIGURE 14: Illustration of experimental setup with evaporation-induced crumpling process and SEM photographs at each sample. Reproduced from [92], copyright 2011, American Chemical Society.

all combinations of solvents and antisolvents can be used to generate robust crumpled rGO as the $\mathrm{C}_{6} \mathrm{H}_{14}-\mathrm{C}_{2} \mathrm{H}_{6} \mathrm{O}$ system [142].

Capillary force can also be used to obtain crumpled GO sheets. It is introduced during the evaporation process for removing water from GO aerosols [92, 145, 146]. Figure 14 shows the typical apparatus for fabricating capillary crumpled GO/rGO [92]. The aerosolization of GO suspension using spray techniques supplies separate GO sheet groups. Meantime, the employed drying process induces the compression of capillary to deform the GO sheets present in aerosols. In evaporation, GO sheets undergo several morphological changes (i.e., from the coffee ring design in aerosol $\rightarrow$ titles + clustered sheets $\rightarrow$ loosely packed + wrinkled sheets having minor water quantities $\rightarrow$ dry + crumpled ball-like structure having multiple ridges and vertices). 
Temperatures beyond $500^{\circ} \mathrm{C}$ can be used for simultaneous reduction of GO. However, the reduction process affects the crumpling conformations [146].

The $\mathrm{GO} / \mathrm{rGO}$ structure obtained by capillary wrinkling is stabilized by plastically deformed $\pi-\pi$ stacked ridges. These have a thickness of around 10s of nanometers and oppose the unfolding and collapsing as normal GO sheets on running under solution, microwave heating, compression, vapor treatment with hydrazine, and thermal shock [92]. Controlled palletization within $55 \mathrm{MPa}$ may reduce the flat graphene sheet surface area from $407 \mathrm{~m}^{2} / \mathrm{g}$ to $66 \mathrm{~m}^{2} / \mathrm{g}$, whereas the surface area during capillary crumpled rGO varies only from $567 \mathrm{~m}^{2} / \mathrm{g}$ to $255 \mathrm{~m}^{2} / \mathrm{g}$. The capillary crumpled rGO balls show tight packing without any reduction in the accessible surface area. This enables less dependence on gravimetric capacitance in electrode mass loading [146]. However, the surface area loss caused by load-bearing compression and large load-dependent capacitances still significantly limited the use of expansion.

\section{Conclusion and Future Research Directions}

The past few decades have reported the evolution of (i) macroscopic (macrofoams, millispheres, fibers, and films) and (ii) microscopic (3D honeycomb-like graphene, hollow spheres, strutted nanostructures, and crumpled sheets) 3D graphene materials. The macroscopic 3D graphene structures can be employed as free-standing units, while the microscopic ones can be turned into arbitrary forms without detailing the restacking issue. As per preconstructed 3D morphologies responsible for preventing the restacking of sheets, the engineering $3 \mathrm{D}$ graphene structures and materials are widely used in energy storage applications, environmental remediation, sensors, etc. The macroscopic structure, convenient surface area, conductivities, pore distribution, mechanical properties, and site density are crucial factors in designing 3D graphene for particular application. The $3 \mathrm{D}$ structure prepared through $3 \mathrm{D}$ self-assembly and reduction is dominating because of its ease of manipulation. Factors like shape, microstructures, functional groups, and dopants of 3D rGO can be achieved by manipulating the GO precursor properties, controlling reaction and reduction conditions, involving additives, and using templates. However, connections between stochastic physical sheets and overstacking of sheets are some of the important issues of the $3 \mathrm{D}$ rGO architecture.

Considerable efforts are needed to precisely manage the defects in resulting 3D materials. Its unique topology and external flaws serve as an active seat for a variety of applications. However, apprehending the role of various disordered sites in different applications is undoubtedly limited. Furthermore, there is still a point of doubt among rich active sites, high conductivities (thermal and electrical), and strong mechanical strength. An accurate control over faulty sites in 3D graphene-based material is key to stabilize this equilibrium and attain an optimum performance.

The versatility of $3 \mathrm{D}$ graphene also requires exploration for new and promising application areas. 3D graphene films can be utilized in thermal or electromagnetic cloaking. With high transmittance, exceptional mechanical properties, and low sheet resistance, the graphene materials are considered next-generation conduction materials for developing transparent electrodes to be applied into strain sensors, touch screens, optoelectronic devices, organic resistive memory, LCDs, LEDs, flexible electronics, and thin-film photovoltaics [147-152]. However, the applicability of graphene layers in other fields gets limited because the sheets tend to restack, resulting in a decrease of surface area and unique characteristics belonging to thin layers. The $3 \mathrm{D}$ graphene structures deliberately eliminate the possibility of face-to-face restacking, expanding the usage of graphene in a broad range of fields. 3D graphene structures can be promising in electrochemical applications like supercapacitors, sensors, fuel cells, hydrogen storage, and flexible electronics [5, 153-160]. Furthermore, 3D graphene materials can be effectively employed as support catalysts in chemical and electrochemical reactions, especially in environmental remedy, where macroscopic structures are advantageous in recycling and recovery.

Also, the microscopic architectures can prove important in scaling the future devices. Various 3D graphene materials also show the scalability of the industry in terms of production and utilization. More importance can be given towards upscaling the lab-based facilities to minimize the production cost. There are high possibilities for 3D graphene materials to overtake markets in the coming years.

\section{Data Availability}

The data used to support the study is included in the article.

\section{Conflicts of Interest}

The authors declare that they have no known competing financial interests or personal relationships that could have appeared to influence the work reported in this paper.

\section{Authors' Contributions}

R.S. was responsible for conceptualization, data curation, formal analysis, methodology, writing of the original draft, and review and editing; N.K., N.R., M.S., D.A.D., and K.ES. were responsible for data curation and review and editing; I.P., C.P.J.I., R.K., and V.V. were responsible for the formal analysis. All authors have read and agreed to the published version of the manuscript.

\section{Acknowledgments}

The authors are grateful to the Dr. S.S. Bhatnagar University Institute of Chemical Engineering \& Technology, Panjab University, India, for their support and assistance with the study. All authors wish everyone a good and healthy life in these tough times of COVID-19.

\section{References}

[1] K. S. Novoselov, A. K. Geim, S. V. Morozov et al., "Electric field effect in atomically thin carbon films," Science, vol. 306, no. 5696, pp. 666-669, 2004. 
[2] A. Balandin, S. Ghosh, W. Bao et al., "Superior thermal conductivity of single-layer graphene," Nano Letters, vol. 8, no. 3, pp. 902-907, 2008.

[3] C. Lee, X. Wei, J. Kysar, and J. Hone, "Measurement of the elastic properties and intrinsic strength of monolayer graphene," Science, vol. 321, no. 5887, pp. 385-388, 2008.

[4] N. Rao, R. Singh, and L. Bashambu, "Carbon-based nanomaterials: synthesis and prospective applications," Materials Today: Proceedings, vol. 44, pp. 608-614, 2021.

[5] R. Singh, "Advancements in energy storage through graphene," in Advances in Materials Processing and Manufacturing Applications. iCADMA 2020, Lecture Notes in Mechanical Engineering, A. Patnaik, E. Kozeschnik, and V. Kukshal, Eds., pp. 165-173, Springer, Singapore, 2021.

[6] R. Singh, M. Singh, N. Kumari, Janak, S. Maharana, and P. Maharana, "A comprehensive review of polymeric wastewater purification membranes," J. Compos. Sci, vol. 5, no. 6, p. 162, 2021.

[7] M. Zeng, W. Wang, and X. Bai, "Preparing three-dimensional graphene architectures: review of recent developments," Chinese Physics B, vol. 22, no. 9, p. 098105, 2013.

[8] Z. Sun, S. Fang, and Y. Hu, "3D graphene materials: from understanding to design and synthesis control," Chemical Reviews, vol. 120, no. 18, pp. 10336-10453, 2020.

[9] Q. Fang, Y. Shen, and B. Chen, "Synthesis, decoration and properties of three-dimensional graphene-based macrostructures: a review," Chemical Engineering Journal, vol. 264, pp. 753-771, 2015.

[10] S. Korkut, J. Roy-Mayhew, D. Dabbs, D. Milius, and I. Aksay, "High surface area tapes produced with functionalized graphene," ACS Nano, vol. 5, no. 6, pp. 5214-5222, 2011.

[11] S. Pei and H. Cheng, "The reduction of graphene oxide," Carbon, vol. 50, no. 9, pp. 3210-3228, 2012.

[12] H. Schniepp, J. Li, M. McAllister et al., "Functionalized single graphene sheets derived from splitting graphite oxide," The Journal Of Physical Chemistry B., vol. 110, no. 17, pp. 85358539, 2006.

[13] M. McAllister, J. Li, D. Adamson et al., "Single sheet functionalized graphene by oxidation and thermal expansion of graphite," Chemistry of Materials., vol. 19, no. 18, pp. 4396-4404, 2007.

[14] S. Stankovich, D. Dikin, R. Piner et al., "Synthesis of graphene-based nanosheets via chemical reduction of exfoliated graphite oxide," Carbon, vol. 45, no. 7, pp. 1558-1565, 2007.

[15] V. Tung, M. Allen, Y. Yang, and R. Kaner, "High-throughput solution processing of large-scale graphene," Nature Nanotechnology, vol. 4, pp. 25-29, 2008.

[16] G. Wang, J. Yang, J. Park et al., "Facile synthesis and characterization of graphene nanosheets," The Journal Of Physical Chemistry C., vol. 112, no. 22, pp. 8192-8195, 2008.

[17] R. Muszynski, B. Seger, and P. Kamat, "Decorating graphene sheets with gold nanoparticles," The Journal Of Physical Chemistry C., vol. 112, pp. 5263-5266, 2008.

[18] S. Stankovich, D. Dikin, G. Dommett et al., "Graphene-based composite materials," Nature, vol. 442, no. 7100, pp. 282286, 2006.

[19] X. Fan, W. Peng, Y. Li et al., "Deoxygenation of exfoliated graphite oxide under alkaline conditions: a green route to graphene preparation," Advanced Materials, vol. 20, no. 23, pp. 4490-4493, 2008.
[20] M. Fernández-Merino, L. Guardia, J. Paredes et al., "Vitamin $\mathrm{C}$ is an ideal substitute for hydrazine in the reduction of graphene oxide suspensions," The Journal Of Physical Chemistry C., vol. 114, no. 14, pp. 6426-6432, 2010.

[21] S. Pei, J. Zhao, J. Du, W. Ren, and H. Cheng, "Direct reduction of graphene oxide films into highly conductive and flexible graphene films by hydrohalic acids," Carbon, vol. 48, pp. 4466-4474, 2010.

[22] G. Williams, B. Seger, and P. Kamat, "TiO2-Graphene Nanocomposites. UV-assisted photocatalytic reduction of graphene oxide," ACS Nano, vol. 2, no. 7, pp. 1487-1491, 2008.

[23] Y. Zhou, Q. Bao, L. Tang, Y. Zhong, and K. Loh, "Hydrothermal dehydration for the "green" reduction of exfoliated graphene oxide to graphene and demonstration of tunable optical limiting properties," Chemistry of Materials, vol. 21, pp. 2950-2956, 2009.

[24] H. Wang, J. Robinson, X. Li, and H. Dai, "Solvothermal reduction of chemically exfoliated graphene sheets," Journal of the American Chemical Society, vol. 131, pp. 9910-9911, 2009.

[25] L. Cote, R. Cruz-Silva, and J. Huang, "Flash reduction and patterning of graphite oxide and its polymer composite," Journal of the American Chemical Society, vol. 131, pp. 11027-11032, 2009.

[26] S. Gilje, S. Dubin, A. Badakhshan, J. Farrar, S. Danczyk, and R. Kaner, "Photothermal deoxygenation of graphene oxide for patterning and distributed ignition applications," Advanced Materials, vol. 22, pp. 419-423, 2010.

[27] D. Sokolov, K. Shepperd, and T. Orlando, "Formation of graphene features from direct laser-induced reduction of graphite oxide," Journal of Physical Chemistry Letters, vol. 1, pp. 2633-2636, 2010.

[28] A. Viinikanoja, Z. Wang, J. Kauppila, and C. Kvarnström, "Electrochemical reduction of graphene oxide and its in situ spectroelectrochemical characterization," Physical Chemistry Chemical Physics, vol. 14, p. 14003, 2012.

[29] Z. Wu, W. Ren, L. Gao et al., "Synthesis of graphene sheets with high electrical conductivity and good thermal stability by hydrogen arc discharge exfoliation," ACS Nano, vol. 3, no. 2, pp. 411-417, 2009.

[30] C. Gómez-Navarro, R. Weitz, A. Bittner et al., "Electronic transport properties of individual chemically reduced graphene oxide sheets," Nano Letters, vol. 7, no. 11, pp. 34993503, 2007.

[31] Y. Zhu, S. Murali, M. Stoller, A. Velamakanni, R. Piner, and R. Ruoff, "Microwave assisted exfoliation and reduction of graphite oxide for ultracapacitors," Carbon, vol. 48, pp. 2118-2122, 2010.

[32] Y. Si and E. Samulski, "Synthesis of water soluble graphene," Nano Letters, vol. 8, pp. 1679-1682, 2008.

[33] W. Gao, L. Alemany, L. Ci, and P. Ajayan, "New insights into the structure and reduction of graphite oxide," Nature Chemistry, vol. 1, pp. 403-408, 2009.

[34] C. Li and G. Shi, "Three-dimensional graphene architectures," Nanoscale, vol. 4, pp. 5549-5563, 2012.

[35] V. Chabot, D. Higgins, A. Yu, X. Xiao, Z. Chen, and J. Zhang, "A review of graphene and graphene oxide sponge: material synthesis and applications to energy and the environment," Energy \& Environmental Science, vol. 7, p. 1564, 2014.

[36] H. Ahn, J. Jang, M. Seol et al., "Self-assembled foam-like graphene networks formed through nucleate boiling," Scientific Reports, vol. 3, no. 1, p. 1396, 2013. 
[37] X. Gao, J. Jang, and S. Nagase, "Hydrazine and thermal reduction of graphene oxide: reaction mechanisms, product structures, and reaction design," The Journal Of Physical Chemistry C., vol. 114, pp. 832-842, 2009.

[38] S. Yin, Z. Niu, and X. Chen, "Assembly of graphene sheets into 3D macroscopic structures," Small, vol. 8, pp. 24582463, 2012.

[39] S. Nardecchia, D. Carriazo, M. Ferrer, M. Gutiérrez, and F. del Monte, "Three dimensional macroporous architectures and aerogels built of carbon nanotubes and/or graphene: synthesis and applications," Chemical Society Reviews, vol. 42, pp. 794-830, 2013.

[40] X. Cao, Z. Yin, and H. Zhang, "Three-dimensional graphene materials: preparation, structures and application in supercapacitors," Energy \& Environmental Science, vol. 7, pp. 1850$1865,2014$.

[41] Y. Ma and Y. Chen, "Three-dimensional graphene networks: synthesis, properties and applications," National Science Review, vol. 2, pp. 40-53, 2014.

[42] H. Wang, X. Yuan, G. Zeng et al., "Three dimensional graphene based materials: synthesis and applications from energy storage and conversion to electrochemical sensor and environmental remediation," Advances in Colloid and Interface Science, vol. 221, pp. 41-59, 2015.

[43] H. Qiu, Y. Guan, P. Luo, and Y. Wang, "Recent advance in fabricating monolithic 3D porous graphene and their applications in biosensing and biofuel cells," Biosensors \& Bioelectronics, vol. 89, pp. 85-95, 2017.

[44] M. Rethinasabapathy, S. M. Kang, S. C. Jang, and Y. S. Huh, "Three-dimensional porous graphene materials for environmental applications," Carbon Lett., vol. 22, pp. 113, 2017.

[45] Y. Lu, Y. Ma, T. Zhang, Y. Yang, L. Wei, and Y. Chen, "Monolithic 3D cross-linked polymeric graphene materials and the likes: preparation and their redox catalytic applications," Journal of the American Chemical Society, vol. 140, pp. 11538-11550, 2018.

[46] Y. Xia, R. Li, R. Chen, J. Wang, and L. Xiang, "3D architectured graphene/metal oxide hybrids for gas sensors: a review," Sensors, vol. 18, p. 1456, 2018.

[47] V. Smirnov, A. Arbuzov, Y. Shul'ga et al., "Photoreduction of graphite oxide," High Energy Chemistry, vol. 45, no. 1, pp. 5761, 2011.

[48] V. Abdelsayed, S. Moussa, H. Hassan, H. Aluri, M. Collinson, and M. El-Shall, "Photothermal deoxygenation of graphite oxide with laser excitation in solution and graphene-aided increase in water temperature," Journal of Physical Chemistry Letters, vol. 1, pp. 2804-2809, 2010.

[49] P. Willmott and J. Huber, "Pulsed laser vaporization and deposition," Reviews of Modern Physics, vol. 72, pp. 315328, 2000.

[50] L. Huang, Y. Liu, L. Ji, Y. Xie, T. Wang, and W. Shi, "Pulsed laser assisted reduction of graphene oxide," Carbon, vol. 49, pp. 2431-2436, 2011.

[51] Y. Guan, Y. Fang, G. Lim, H. Zheng, and M. Hong, "Fabrication of laser-reduced graphene oxide in liquid nitrogen environment," Scientific Reports, vol. 6, p. 28913, 2016.

[52] W. Gao, N. Singh, L. Song et al., "Direct laser writing of micro-supercapacitors on hydrated graphite oxide films," Nature Nanotechnology, vol. 6, no. 8, pp. 496-500, 2011.
[53] H. Tian, Y. Yang, D. Xie et al., "Wafer-scale integration of graphene-based electronic, optoelectronic and electroacoustic devices," Scientific Reports, vol. 4, no. 1, p. 3598, 2015.

[54] B. Senyuk, N. Behabtu, A. Martinez et al., "Three-dimensional patterning of solid microstructures through laser reduction of colloidal graphene oxide in liquid-crystalline dispersions," Nature Communications, vol. 6, no. 1, pp. 1-7, 2015.

[55] Y. Zhang, L. Guo, H. Xia, Q. Chen, J. Feng, and H. Sun, "Photoreduction of graphene oxides: methods, properties, and applications," Advanced Optical Materials, vol. 2, pp. 10-28, 2013.

[56] M. El-Kady, V. Strong, S. Dubin, and R. Kaner, "Laser scribing of high-performance and flexible graphene-based electrochemical capacitors," Science, vol. 335, pp. 1326-1330, 2012.

[57] V. Strong, S. Dubin, M. F. el-Kady et al., "Patterning and electronic tuning of laser scribed graphene for flexible all-carbon devices," ACS Nano, vol. 6, no. 2, pp. 1395-1403, 2012.

[58] J. Lu, X. Zhang, Q. Zhu et al., "Highly tunable and scalable fabrication of 3D flexible graphene micropatterns for directing cell alignment," ACS Applied Materials \& Interfaces, vol. 10, no. 21, pp. 17704-17713, 2018.

[59] D. Bhattacharjya, C. Kim, J. Kim, I. You, J. In, and S. Lee, "Fast and controllable reduction of graphene oxide by lowcost $\mathrm{CO}_{2}$ laser for supercapacitor application," Applied Surface Science, vol. 462, pp. 353-361, 2018.

[60] D. Sokolov, C. Rouleau, D. Geohegan, and T. Orlando, "Excimer laser reduction and patterning of graphite oxide," Carbon, vol. 53, pp. 81-89, 2013.

[61] C. Chua and M. Pumera, "Chemical reduction of graphene oxide: a synthetic chemistry viewpoint," Chemical Society Reviews, vol. 43, pp. 291-312, 2014.

[62] K. Sheng, Y. Sun, C. Li, W. Yuan, and G. Shi, "Ultrahigh-rate supercapacitors based on eletrochemically reduced graphene oxide for ac line-filtering," Scientific Reports, vol. 2, p. 247, 2012

[63] W. Chen, P. Xiao, H. Chen, H. Zhang, Q. Zhang, and Y. Chen, "Polymeric graphene bulk materials with a 3D cross-linked monolithic graphene network," Advanced Materials, vol. 31, p. 1802403, 2018.

[64] W. Chen and L. Yan, "In situ self-assembly of mild chemical reduction graphene for three-dimensional architectures," Nanoscale, vol. 3, pp. 3132-3137, 2011.

[65] H. Pham, V. Pham, T. Cuong et al., "Synthesis of the chemically converted graphene xerogel with superior electrical conductivity," Chemical Communications, vol. 47, no. 34, pp. 9672-9674, 2011.

[66] C. Liu, H. Liu, A. Xu, K. Tang, Y. Huang, and C. Lu, "In situ reduced and assembled three-dimensional graphene aerogel for efficient dye removal," Journal of Alloys and Compounds, vol. 714, pp. 522-529, 2017.

[67] K. Sheng, Y. Xu, C. Li, and G. Shi, "High-performance selfassembled graphene hydrogels prepared by chemical reduction of graphene oxide," New Carbon Materials, vol. 26, pp. 9-15, 2011.

[68] L. Zhang and G. Shi, "Preparation of highly conductive graphene hydrogels for fabricating supercapacitors with high rate capability," Journal of Physical Chemistry C, vol. 115, pp. 17206-17212, 2011.

[69] W. Wei, K. Sun, and Y. Hu, "Synthesis of mesochannel carbon nanowall material from $\mathrm{CO}_{2}$ and its excellent 
performance for perovskite solar cells," Industrial and Engineering Chemistry Research, vol. 56, pp. 1803-1809, 2017.

[70] L. Chang, D. Stacchiola, and Y. Hu, "Design and synthesis of $3 \mathrm{D}$ potassium-ion pre-intercalated graphene for supercapacitors," Industrial and Engineering Chemistry Research, vol. 57, pp. 3610-3616, 2018.

[71] Z. Xing, B. Wang, W. Gao et al., "Reducing $\mathrm{CO}_{2}$ to dense nanoporous graphene by $\mathrm{Mg} / \mathrm{Zn}$ for high power electrochemical capacitors," Nano Energy, vol. 11, pp. 600-610, 2015.

[72] X. Zhang, D. Liu, L. Yang, L. Zhou, and T. You, "Self-assembled three-dimensional graphene-based materials for dye adsorption and catalysis," Journal of Materials Chemistry A, vol. 3, pp. 10031-10037, 2015.

[73] J. Luo, J. Lai, N. Zhang, Y. Liu, R. Liu, and X. Liu, “Tannic acid induced self-assembly of three-dimensional graphene with good adsorption and antibacterial properties," ACS Sustainable Chemistry \& Engineering, vol. 4, pp. 1404-1413, 2016.

[74] L. Zhang, G. Chen, M. Hedhili, H. Zhang, and P. Wang, "Three-dimensional assemblies of graphene prepared by a novel chemical reduction-induced self-assembly method," Nanoscale, vol. 4, pp. 7038-7045, 2012.

[75] M. Chen, C. Zhang, X. Li et al., "A one-step method for reduction and self-assembling of graphene oxide into reduced graphene oxide aerogels," Journal of Materials Chemistry A, vol. 1, no. 8, pp. 2869-2877, 2013.

[76] S. Yang, L. Zhang, Q. Yang et al., "Graphene aerogel prepared by thermal evaporation of graphene oxide suspension containing sodium bicarbonate," Journal of Materials Chemistry A, vol. 3, no. 15, pp. 7950-7958, 2015.

[77] X. Zhang, Z. Sui, B. Xu et al., "Mechanically strong and highly conductive graphene aerogel and its use as electrodes for electrochemical power sources," Journal of Materials Chemistry, vol. 21, no. 18, pp. 6494-6497, 2011.

[78] C. Hu, X. Zhai, L. Liu, Y. Zhao, L. Jiang, and L. Qu, "Spontaneous Reduction and assembly of graphene oxide into threedimensional graphene network on arbitrary conductive substrates," Scientific Reports, vol. 3, p. 2065, 2013.

[79] Z. Niu, J. Chen, H. Hng, J. Ma, and X. Chen, "A leavening strategy to prepare reduced graphene oxide foams," Advanced Materials, vol. 24, pp. 4144-4150, 2012.

[80] Y. Xu, G. Shi, and X. Duan, "Self-assembled threedimensional graphene macrostructures: synthesis and applications in supercapacitors," Accounts of Chemical Research, vol. 48, pp. 1666-1675, 2015.

[81] K. Chen, L. Chen, Y. Chen, H. Bai, and L. Li, “Three-dimensional porous graphene-based composite materials: electrochemical synthesis and application," Journal of Materials Chemistry, vol. 22, pp. 20968-20976, 2012.

[82] V. Pham, T. Gebre, and J. Dickerson, "Facile electrodeposition of reduced graphene oxide hydrogels for highperformance supercapacitors," Nanoscale, vol. 7, pp. 59475950, 2015.

[83] Y. Li, K. Sheng, W. Yuan, and G. Shi, "A high-performance flexible fibre-shaped electrochemical capacitor based on electrochemically reduced graphene oxide," Chemical Communications, vol. 49, pp. 291-293, 2013.

[84] T. Purkait, G. Singh, D. Kumar, M. Singh, and R. Dey, "Highperformance flexible supercapacitors based on electrochemically tailored three-dimensional reduced graphene oxide networks," Scientific Reports, vol. 8, p. 640, 2018.
[85] J. Quezada-Renteria, C. Ania, L. Chazaro-Ruiz, and J. RangelMendez, "Influence of protons on reduction degree and defect formation in electrochemically reduced graphene oxide," Carbon, vol. 149, pp. 722-732, 2019.

[86] C. Wu, X. Wang, Q. Zhuo et al., “A facile continuous wetspinning of graphene oxide fibers from aqueous solutions at high $\mathrm{pH}$ with the introduction of ammonia," Carbon, vol. 138, pp. 292-299, 2018.

[87] C. Chen, Q. Zhang, M. Yang, C. Huang, Y. Yang, and M. Wang, "Structural evolution during annealing of thermally reduced graphene nanosheets for application in supercapacitors," Carbon, vol. 50, pp. 3572-3584, 2012.

[88] C. Chen, Q. Zhang, C. Huang et al., "Macroporous 'bubble' graphene film via template-directed ordered-assembly for high rate supercapacitors," Chemical Communications, vol. 48, no. 57, pp. 7149-7151, 2012.

[89] W. Liu, H. Li, Q. Zeng et al., "Fabrication of ultralight threedimensional graphene networks with strong electromagnetic wave absorption properties," Journal of Materials Chemistry A, vol. 3, no. 7, pp. 3739-3747, 2015.

[90] J. Huang, X. Liu, Q. Zhang et al., "Entrapment of sulfur in hierarchical porous graphene for lithium-sulfur batteries with high rate performance from -40 to $60^{\circ} \mathrm{C}$," Nano Energy, vol. 2, no. 2, pp. 314-321, 2013.

[91] R. Fang, S. Zhao, S. Pei et al., "Toward more reliable lithiumsulfur batteries: an all-graphene cathode structure," ACS Nano, vol. 10, no. 9, pp. 8676-8682, 2016.

[92] J. Luo, H. Jang, T. Sun et al., "Compression and aggregationresistant particles of crumpled soft sheets," ACS Nano, vol. 5, no. 11, pp. 8943-8949, 2011.

[93] Y. Xu, K. Sheng, C. Li, and G. Shi, "Self-assembled graphene hydrogel via a one-step hydrothermal process," ACS Nano, vol. 4, pp. 4324-4330, 2010.

[94] Y. Xu, Z. Lin, X. Zhong et al., "Holey graphene frameworks for highly efficient capacitive energy storage," Nature Communications, vol. 5, no. 1, 2014.

[95] Z. Sui and B. Han, "Effect of surface chemistry and textural properties on carbon dioxide uptake in hydrothermally reduced graphene oxide," Carbon, vol. 82, pp. 590-598, 2015.

[96] Z. Wu, Y. Sun, Y. Tan, S. Yang, X. Feng, and K. Müllen, "Three-dimensional graphene-based macro- and mesoporous frameworks for high-performance electrochemical capacitive energy storage," Journal of the American Chemical Society, vol. 134, pp. 19532-19535, 2012.

[97] J. Kim, J. Oh, M. Kotal, N. Koratkar, and I. Oh, "Self-assembly and morphological control of three-dimensional macroporous architectures built of two-dimensional materials," Nano Today, vol. 14, pp. 100-123, 2017.

[98] H. Bi, K. Yin, X. Xie et al., "Low temperature casting of graphene with high compressive strength," Advanced Materials, vol. 24, no. 37, pp. 5124-5129, 2012.

[99] K. Hu, X. Xie, T. Szkopek, and M. Cerruti, "Understanding hydrothermally reduced graphene oxide hydrogels: from reaction products to hydrogel properties," Chemistry of Materials, vol. 28, pp. 1756-1768, 2016.

[100] A. Goldstein, W. Mickelson, A. Machness et al., "Simultaneous sheet cross-linking and deoxygenation in the graphene oxide sol-gel transition," Journal of Physical Chemistry C, vol. 118, no. 49, pp. 28855-28860, 2014.

[101] X. Wu, J. Zhou, W. Xing et al., "High-rate capacitive performance of graphene aerogel with a superhigh $\mathrm{C} / \mathrm{O}$ molar 
ratio," Journal of Materials Chemistry, vol. 22, no. 43, pp. 23186-23193, 2012.

[102] J. Ma, J. Wang, Y. He et al., "A solvothermal strategy: onestep in situ synthesis of self-assembled 3D graphene-based composites with enhanced lithium storage capacity," Journal of Materials Chemistry A, vol. 2, no. 24, pp. 9200-9207, 2014.

[103] J. Ma, Y. He, W. Zhang et al., “An experimental insight into the advantages of _in situ_solvothermal route to construct 3D graphene-based anode materials for lithium-ion batteries," Nano Energy, vol. 16, pp. 235-246, 2015.

[104] Y. Sun, Q. Wu, and G. Shi, "Supercapacitors based on selfassembled graphene organogel," Physical Chemistry Chemical Physics, vol. 13, pp. 17249-17254, 2011.

[105] Y. Wu, N. Yi, L. Huang et al., "Three-dimensionally bonded spongy graphene material with super compressive elasticity and near-zero Poisson's ratio," Nature Communications, vol. 6, no. 1, p. 6141, 2015.

[106] L. Qiu, J. Liu, S. Chang, Y. Wu, and D. Li, "Biomimetic superelastic graphene-based cellular monoliths," Nature Communications, vol. 3, p. 1241, 2012.

[107] Z. Li, T. Huang, W. Gao et al., "Hydrothermally activated graphene fiber fabrics for textile electrodes of supercapacitors," ACS Nano, vol. 11, no. 11, pp. 11056-11065, 2017.

[108] C. Nethravathi and M. Rajamathi, "Chemically modified graphene sheets produced by the solvothermal reduction of colloidal dispersions of graphite oxide," Carbon, vol. 46, pp. 1994-1998, 2008.

[109] Y. Shao, M. F. el-Kady, C. Lin et al., “3D Freeze-casting of cellular graphene films for ultrahigh-power-density supercapacitors," Advanced Materials, vol. 28, no. 31, pp. 6719-6726, 2016.

[110] J. Kuang, L. Liu, Y. Gao et al., “A hierarchically structured graphene foam and its potential as a large-scale strain-gauge sensor," Nanoscale, vol. 5, no. 24, p. 12171, 2013.

[111] W. Li, K. Lu, and J. Walz, "Freeze casting of porous materials: review of critical factors in microstructure evolution," International Materials Review, vol. 57, pp. 37-60, 2012.

[112] J. Wang and M. Ellsworth, "Graphene aerogels," ECS Meeting Abstracts., vol. 19, p. 5, 2009.

[113] H. Bai, C. Li, X. Wang, and G. Shi, "On the gelation of graphene oxide," Journal of Physical Chemistry C, vol. 115, pp. 5545-5551, 2011.

[114] H. Geng, X. Liu, G. Shi et al., "Graphene oxide restricts growth and recrystallization of ice crystals," Angewandte Chemie, International Edition, vol. 56, no. 4, pp. 997-1001, 2017.

[115] C. Wang, X. Chen, B. Wang et al., "Freeze-casting produces a graphene oxide aerogel with a radial and centrosymmetric structure," ACS Nano, vol. 12, no. 6, pp. 5816-5825, 2018.

[116] X. Xu, Q. Zhang, Y. Yu, W. Chen, H. Hu, and H. Li, "Naturally dried graphene aerogels with superelasticity and tunable Poisson's ratio," Advanced Materials, vol. 28, pp. 9223-9230, 2016.

[117] X. Xie, Y. Zhou, H. Bi, K. Yin, S. Wan, and L. Sun, "Largerange control of the microstructures and properties of three-dimensional porous graphene," Scientific Reports, vol. 3, p. 2177, 2013.

[118] H. Bai, Y. Chen, B. Delattre, A. Tomsia, and R. Ritchie, "Bioinspired large-scale aligned porous materials assembled with dual temperature gradients," Science Advances, vol. 1, article e1500849, 2015.
[119] M. Yang, N. Zhao, Y. Cui et al., "Biomimetic architectured graphene aerogel with exceptional strength and resilience," ACS Nano, vol. 11, no. 7, pp. 6817-6824, 2017.

[120] Y. Lin, F. Liu, G. Casano, R. Bhavsar, I. Kinloch, and B. Derby, "Pristine graphene aerogels by room-temperature freeze gelation," Advanced Materials, vol. 28, pp. 79938000, 2016.

[121] C. Zhu, T. Han, E. Duoss et al., "Highly compressible 3D periodic graphene aerogel microlattices," Nature Communications, vol. 6, no. 1, pp. 1-8, 2015.

[122] E. García-Tuñon, S. Barg, J. Franco et al., "Printing in three dimensions with graphene," Advanced Materials, vol. 27, no. 10, pp. 1688-1693, 2015.

[123] R. Hensleigh, H. Cui, J. Oakdale et al., "Additive manufacturing of complex micro-architected graphene aerogels," Materials Horizons, vol. 5, no. 6, pp. 1035-1041, 2018.

[124] J. Lewis, "Direct ink writing of 3D functional materials," Advanced Functional Materials, vol. 16, pp. 2193-2204, 2006.

[125] J. Kim, W. Chang, D. Kim et al., "3D printing of reduced graphene oxide nanowires," Advanced Materials, vol. 27, no. 1, pp. 157-161, 2015.

[126] K. Fu, Y. Yao, J. Dai, and L. Hu, "Progress in 3D printing of carbon materials for energy-related applications," Advanced Materials, vol. 29, p. 1603486, 2016.

[127] J. Smay, J. Cesarano, and J. Lewis, "Colloidal inks for directed assembly of 3-D periodic structures," Langmuir, vol. 18, pp. 5429-5437, 2002.

[128] C. Bao, H. Zhang, C. Wilkie et al., "On the dispersion systems of graphene-like two-dimensional materials: from fundamental laws to engineering guidelines," Carbon, vol. 107, pp. 774-782, 2016.

[129] J. Ma, P. Wang, L. Dong, Y. Ruan, and H. Lu, "Highly conductive, mechanically strong graphene monolith assembled by three-dimensional printing of large graphene oxide," Journal of Colloid and Interface Science, vol. 534, pp. 12-19, 2019.

[130] Y. Yao, K. Fu, C. Yan et al., "Three-dimensional printable high-temperature and high-rate heaters," ACS Nano, vol. 10, no. 5, pp. 5272-5279, 2016.

[131] C. Zhu, T. Liu, F. Qian et al., "Supercapacitors based on threedimensional hierarchical graphene aerogels with periodic macropores," Nano Letters, vol. 16, no. 6, pp. 3448-3456, 2016.

[132] Y. Jiang, Z. Xu, T. Huang et al., "Direct 3D Printing of ultralight graphene oxide aerogel microlattices," Advanced Functional Materials, vol. 28, no. 16, p. 1707024, 2018.

[133] X. Tang, H. Zhou, Z. Cai et al., "Generalized 3D printing of graphene-based mixed-dimensional hybrid aerogels," ACS Nano, vol. 12, no. 4, pp. 3502-3511, 2018.

[134] Q. Zhang, F. Zhang, S. Medarametla, H. Li, C. Zhou, and D. Lin, "3D Printing of graphene aerogels," Small, vol. 12, pp. 1702-1708, 2016.

[135] Z. Xu, Y. Zhang, P. Li, and C. Gao, "Strong, conductive, lightweight, neat graphene aerogel fibers with aligned pores," ACS Nano, vol. 6, pp. 7103-7113, 2012.

[136] H. Cong, X. Ren, P. Wang, and S. Yu, "Wet-spinning assembly of continuous, neat and macroscopic graphene fibers," Scientific Reports, vol. 2, p. 613, 2012.

[137] Y. Zhao, C. Jiang, C. Hu et al., "Large-scale spinning assembly of neat, morphology-defined, graphene-based hollow fibers," ACS Nano, vol. 7, no. 3, pp. 2406-2412, 2013. 
[138] Z. Xu and C. Gao, "Graphene chiral liquid crystals and macroscopic assembled fibres," Nature Communications, vol. 2, p. 571, 2011.

[139] L. Kou, Z. Liu, T. Huang et al., "Wet-spun, porous, orientational graphene hydrogel films for high-performance supercapacitor electrodes," Nanoscale, vol. 7, no. 9, pp. 40804087, 2015.

[140] X. Zhao, W. Yao, W. Gao, H. Chen, and C. Gao, "Wet-spun superelastic graphene aerogel millispheres with group effect," Advanced Materials, vol. 29, p. 1701482, 2017.

[141] S. Peurifoy, E. Castro, F. Liu et al., "Three-dimensional graphene nanostructures," Journal of the American Chemical Society, vol. 140, no. 30, pp. 9341-9345, 2018.

[142] Y. Yoon, K. Lee, C. Baik et al., "Anti-solvent derived nonstacked reduced graphene oxide for high performance supercapacitors," Advanced Materials, vol. 25, no. 32, pp. 44374444, 2013.

[143] H. Chen, C. Chen, Y. Liu et al., "High-quality graphene microflower design for high-performance Li-S and Al-Ion batteries," Advanced Energy Materials, vol. 7, no. 17, p. $1700051,2017$.

[144] K. Wu, K. Du, and G. Hu, "A novel design concept for fabricating 3D graphene with the assistant of anti-solvent precipitated sulphates and its Li-ion storage properties," Journal of Materials Chemistry A, vol. 6, pp. 3444-3453, 2018.

[145] J. Luo, H. Jang, and J. Huang, "Effect of sheet morphology on the scalability of graphene-based ultracapacitors," ACS Nano, vol. 7, pp. 1464-1471, 2013.

[146] X. Ma, M. Zachariah, and C. Zangmeister, "Crumpled nanopaper from graphene oxide," Nano Letters, vol. 12, pp. 486489, 2011.

[147] A. Sakhaee-Pour, M. Ahmadian, and A. Vafai, "Potential application of single-layered graphene sheet as strain sensor," Solid State Communications, vol. 147, pp. 336-340, 2008.

[148] J. Wassei and R. Kaner, "Graphene, a promising transparent conductor,” Materials Today, vol. 13, pp. 52-59, 2010.

[149] G. Divyapriya, P. Thangadurai, and I. Nambi, "Green approach to produce a graphene thin film on a conductive LCD matrix for the oxidative transformation of ciprofloxacin," ACS Sustainable Chemistry \& Engineering, vol. 6, pp. 3453-3462, 2018.

[150] Q. Sun, J. Liu, Y. Peng, A. Wang, Z. Wu, and M. Chen, "Effective heat dissipation of high-power LEDs through creation of three-dimensional ceramic substrate with kaolin/graphene suspension," Journal Of Alloys And Compounds., vol. 817, p. 152779, 2020.

[151] Y. Zhong, Z. Zhen, and H. Zhu, "Graphene: fundamental research and potential applications," Flatchem, vol. 4, pp. 20-32, 2017.

[152] T. Wang, D. Huang, Z. Yang et al., “A review on graphenebased gas/vapor sensors with unique properties and potential applications," Nano-Micro Letters., vol. 8, no. 2, pp. 95-119, 2016.

[153] R. Singh, N. Kaur, and M. Singh, "Bio-compatible bio-fuel cells for medical devices," Materials Today: Proceedings., vol. 44, pp. 242-249, 2021.

[154] M. Cao, J. Su, S. Fan, H. Qiu, D. Su, and L. Li, "Wearable piezoresistive pressure sensors based on 3D graphene," Chemical Engineering Journal, vol. 406, p. 126777, 2021.
[155] W. Zhang, C. Xu, C. Ma et al., "Nitrogen-superdoped 3D graphene networks for high-performance supercapacitors," Advanced Materials, vol. 29, no. 36, p. 1701677, 2017.

[156] R. Singh, A. Altaee, and S. Gautam, "Nanomaterials in the advancement of hydrogen energy storage," Heliyon., vol. 6, article e04487, 2020.

[157] V. Silva, W. Fernandes-Junior, D. Rocha et al., "3D-printed reduced graphene oxide/polylactic acid electrodes: a new prototyped platform for sensing and biosensing applications," Biosensors And Bioelectronics., vol. 170, p. 112684, 2020.

[158] B. Guo, G. Liang, S. Yu, Y. Wang, C. Zhi, and J. Bai, “3D printing of reduced graphene oxide aerogels for energy storage devices: a paradigm from materials and technologies to applications," Energy Storage Materials., vol. 39, pp. 146165, 2021.

[159] D. Xu, C. Xuan, X. Li et al., "Novel helical carbon nanotubesembedded reduced graphene oxide in three- dimensional architecture for high-performance flexible supercapacitors," Electrochimica Acta, vol. 339, p. 135912, 2020.

[160] A. Smith, A. LaChance, S. Zeng, B. Liu, and L. Sun, "Synthesis, properties, and applications of graphene oxide/reduced graphene oxide and their nanocomposites," Nano Materials Science., vol. 1, pp. 31-47, 2019. 